\title{
Strategic Planning in Small and Medium Enterprises (SMEs): A Case Study of Botswana SMEs
}

\author{
Nomsa Sisi Majama ${ }^{1} \&$ Tebogo Israel 'Teddy' Magang ${ }^{2}$ \\ ${ }^{1}$ Local Enterprise Authority, Molepolole, Botswana \\ ${ }^{2}$ Faculty of Business, University of Botswana, Gaborone, Botswana \\ Correspondence: Tebogo Israel 'Teddy' Magang, Lecturer, Faculty of Business, University of Botswana, Private Bag \\ UB 0022, Gaborone, Botswana.
}

Received: February 3, 2017

Accepted: February 17, 2017

Online Published: February 21, 2017

doi:10.5430/jms.v8n1p74

URL: http://dx.doi.org/10.5430/jms.v8n1p74

\begin{abstract}
Although small and medium enterprises contribute immensely to the economy of a country, they are characterised by low performance and high failure rate which is often blamed on lack of resources such as funds, land and skilled labour. Many business management specialists argue that even on the availability of such resources, some SMEs still fail due to lack of strategic planning. Extent literature indicates that formal strategic planning improves business performance as it involves deriving a game plan that enables SMEs to anticipate and respond to the turbulent market by arranging their resources and capabilities accordingly.

As such, this research investigates the status of strategic planning by SMEs in Botswana. The study also investigates the perceived value of Strategic Planning by SME owner managers, and the extent of planning as well as identifying the barriers that prevent effective strategic planning. Using semi-structured interviews of 36 Small and Medium firms selected across several sectors, the study finds that strategic planning efforts do exist within SMEs but most of these firms engage in strategic planning activities to a limited extent. The study also finds several barriers, which contribute to lack of strategic planning. For instance, the study finds that most SME owner/managers have limited knowledge in the area of strategic planning. Some indicated that they do not plan because of the size of the business. Whereas some admitted that they still possess the traditional based thinking where most business decisions are based on intuition. The findings of this study have implications for policy decision makers and SME owner managers.
\end{abstract}

Keywords: strategic planning, small medium enterprises, owner manager, environmental scanning, strategic approach, strategic decisions

\section{Introduction}

Small and Medium Enterprises (SMEs) are a vital component in economic development in countries around the world (Nkwe, 2012; Wang et al., 2007 and Ghobadian and O'Regan, 2002). Even though SMEs contribute significantly to economic development, they are susceptible to poor performance and ultimately collapse. As such, this study seeks to investigate the extent of strategic planning and the perceived value for strategic planning by SMEs. The study also seeks to investigate factors which may impede SMEs from engaging in strategic planning activities in pursuit of their objectives, in Botswana.

Extant literature indicates that there is no universal definition of SMEs, the definition varies and depends on the countries' specific interpretation (OECD, 2013). In an attempt to clear this confusion the EU set up some definition which stipulated that medium sized businesses are those that have less than 250 employees whilst small business have less than 50 employees and micro with less than 10 employees (Christodoulou, 2009). Despite this definition, different countries and establishments use different criteria to define SMEs.

For instance, in Botswana the definition of SME is defined in terms of size, employment levels, and annual turnover as depicted in Table 1, SMEs threshold in Botswana: 
Table 1. SMEs threshold in Botswana

\begin{tabular}{cllll}
\hline Item & Size category & Employment levels & $\begin{array}{c}\text { Annual Turnover in } \\
\text { (Botswana Pula) }\end{array}$ & \multicolumn{1}{c}{$\begin{array}{c}\text { In US\$ Dollar } \\
\text { (Equivalent) }\end{array}$} \\
\hline 1. & Micro Enterprise & Less than 6 workers & Less than P60 000 & US\$7200 \\
\hline 2. & Small Enterprise & Less than 25 workers & $\begin{array}{l}\text { Between P60 000 and P1 } \\
500000\end{array}$ & $\begin{array}{l}\text { Between US } \$ 7200 \text { and } \\
\text { US\$180 000 }\end{array}$ \\
\hline 3. & Medium & Less than 100 workers & $\begin{array}{l}\text { Between P1 500 000 and } \\
\text { P5 000 000 }\end{array}$ & $\begin{array}{l}\text { Between US } \$ 180000 \text { and } \\
\text { US } \$ 600000\end{array}$ \\
\hline
\end{tabular}

Source: BICA (2013)

As such, the definition of SMEs for the purpose of this study is in accordance with SME threshold in Botswana (Table 1).

\subsection{Strategic Planning}

Strategic planning is a process of coordinating activities to achieve the organisation's long term goals. In Hough et al. (2008), it is defined as putting together an action plan for running the business and conducting operations. The authors further elaborate that moulding a strategy represents a commitment to pursue a particular set of actions directed at growing the business. This includes combined efforts to attract and please customers, compete successfully and conducting operations in a way to improve the company's financial performance. Strategic planning is also defined by Drucker (2004) as the continuous process of making entrepreneurial decisions systematically and with their greatest knowledge organizing systematically the efforts to carry out these decisions and measuring the results against the expectations through organized feedback. Kraus et al. (2007, p. 3) argues that "strategic planning is an attempt to prepare for future contingencies and thus to account for environmental dynamics and complexities". Planning entails guidelines on how to achieve desired goals and objectives. Strategic planning gives direction and forms the basis of decision making within the business. Hough et al. $(2008$, p. 4) pointed out that, in evaluating a company's prospects, managers are faced with the following questions: Who are we? Where do we want to go? And how do we get there? In trying to respond to these questions, managers are forced to evaluate the company's current situation and develop a game plan that is capable of moving them in that intended direction. In other words, strategic planning is concerned with identifying foreseeable thrusts and weaknesses to avoid and strengths and opportunities to pursue. Strategic planning is the effective application of the best alternative information to decisions that have to be made to ensure a secure future, this was put forward by Day (1997) cited in (Eusebio and Miclat, 2005).

\subsection{Role of SMEs in Economic Development}

The small and medium enterprises (SMEs) play a major role in the growth of the economy of a country. As affirmed by Veskaisri et al. (2007), SMEs contribute to the Gross Domestic Product (GDP) and create employment to a significant number of members of the public. Small and medium enterprises are said to form the base of industrial structures. According to Balasundaram (2009), they facilitate the process of industrialization in most countries irrespective of their stages of development. In a study to examine the role played by SMEs in developing countries in Botswana, Nkwe (2012) argues that SMEs are vital in achieving economic and social development goals. The researcher maintains that, SMEs contribute to poverty alleviation, employment creation and generation of potential entrepreneurs. Small and Medium-sized enterprises (SMEs) play a central role in the economy. They are a major source of entrepreneurial skills, innovation and employment. Although SMEs are recognized as a source of employment and economic diversification, SME management often suffer from insufficient entrepreneurial and managerial skills (Wang et al., 2007). For instance, in Botswana, Pansiri and Temtime (2008, p. 252) find that 'SME managers/owners normally start a business with little or no basic business management skills'. In their view, SMEs are regularly characterized by lack of coordination, monitoring and strategic orientation. Kraus et al. (2007) affirm that planning in SMEs is irregular and based on intuition with planning instruments used by only a small number of individuals. It is for these reasons that the value of strategic planning by SMEs should be examined in more detail.

Research indicates that most small and medium sized enterprises (SMEs) do not engage in strategic planning (Sandberg et al., 2001; Beaver, 2003;Kraus et al., 2007; Wang et al.,2007; Gunther and Menzel, 2012). This is in contradiction with much of the available literature (Sandada, 2015; Herath and Mahmood, 2013; Kee-Luen et al., 2013 and Karabut and Efendioglu, 2010) on strategy that dictate that enterprises must actively plan for the future in order to survive in the aggressive market as well as build and sustain competitive advantage. By neglecting strategic planning, the organisation will not grow and will struggle to improve performance which will consequently result in 
their ultimate collapse. Accordingly, 'a company's strategy consists of the competitive moves and business approaches that managers employ to grow the business, compete successfully and achieve the targeted levels of organizational performance' (Hough et al., 2008, p.4). SME owner-managers have been characterised as lacking business management skills. Pansiri and Temtime (2008) mentioned that the most common cause of business failure is poor management skills. This position is supported by Wang et al. (2007), who argue that, 'SME owner-managers are strategically "myopic", and that they lack the long term vision of where their company is headed' (Wang et al., 2007, p.1). Ghobadian and O'Regan (2002) put forward that ownership should be considered a critical factor in the strategic direction of small and medium-sized enterprises.

However, literature on SMEs has paid little attention to the strategy-making processes of small and medium-sized firms (SMEs), or to the effectiveness of strategic planning in the SME sector. Much of the existing literature focused on factors inhibiting the growth of SMEs in general (e.g. Cant and Wild, 2013; Okpara, 2011; Mbonyane and Ladzani, 2011; Olawale and Garwe, 2010; Abor and Quartely, 2010; Robson and Obeng, 2008; Okpara and Wynn, 2007; Temtime and Pansiri, 2004) whereas some concentrated on access to finance as a growth constraint (e.g. Chisasa and Makina, 2012; Abor, 2007; Beck and Demirguc-Kunt, 2006; Carpenter and Petersen, 2002). This study therefore aims to add to the thin literature on strategic planning in SMEs by investigating strategic planning practices of SMEs in Botswana. Also most of the studies on SMEs have been disproportionately concentrated in the developed world. Further, extent literature has not paid attention to the issue of strategic planning in SMEs.

\subsection{Problem Statement}

'SMEs are the backbone of modern economies and they generate a large share of jobs' (Burton et al., 2012, p. 183). In Botswana Pansiri and Temtime (2008) argue in their study on managerial skill for SME capacity building that SMEs are not only important for employment creation but are also regarded as the driver behind economic diversification. The authors posit that it is for this reason that efforts are concentrated towards the development of these enterprises. However, the pace of development of SMEs is very slow and diminishing. In spite of their many contributions, SMEs are "plagued by high failure rates and poor performance levels" (Jocumsen, 2004, p. 659).

Regardless of their significant contribution to the country's economy, researches (e.g. Okurut et al., 2011 and Temtime and Pansiri, 2006) have revealed a high failure rate, estimated to be above $80 \%$ in SMEs across all industries in developing countries such as Botswana. SMEs become restrained in globalized environments and this is due to the many problems they are faced with. According to these studies, lack of financing, rapid technological changes, limited managerial capabilities and low productivity are associated with the failure of SMEs.

Though the above have been found to be dominating factors linked to the failure of SMEs, little attention has been paid to the effectiveness of strategic planning in the SME sector. This is in spite of the fact that long term planning and strategic thinking can be a major contributing aspect to their development (Adendorff et al., 2011).

This study therefore aims to investigate the degree to which strategic planning is deployed by SMEs in Botswana. The study also seeks to investigate the importance SME owner-managers perceive strategic planning to be and lastly identify factors that contribute to less planning in SMEs as opposed to large enterprises. In order to investigate these aspects, the following main research questions of the study are developed;

1. To what extent do SMEs formulate strategic plans that guide the overall operations in Botswana?

2. What are the perceptions of SME owner/managers regarding the importance of strategic planning in Botswana?

3. What challenges do SMEs face in adopting strategic planning practices in Botswana?

\subsection{Significance of the Study}

This study extends the literature on SMEs by investigating strategic planning in this area, which is another factor that may also affect performance of SMEs. The study may also be of benefit to SMEs since it investigates elements of planning process and the importance of strategic planning which may be incorporated to improve on the strategic planning activity, this will be of value to SME owner/managers.

The study will also be of value to policy decision makes with regard to regulations governing SME trade. The results of the study may also be of benefit to national policies that aim at supporting small and medium enterprises. Entrepreneurial development agencies such as the Local Enterprise Authority (LEA) and the Citizen Entrepreneurial Agency (CEDA) that were set up to assist in establishment and development of SMEs in Botswana may benefit from the results of this study in terms of challenges and or weaknesses afflicting SMEs. The results of the study could also be used as a guide by SME owner-managers to successfully formulate and implement strategic plans that will enable 
them to survive in the harsh competitive environment. Further the study will contribute to the thin literature on strategic planning in SMEs. It would also serve as a source of reference for other studies.

\section{Literature Review \& Theoretical Framework}

\subsection{Literature Review}

Research in strategic planning by SMEs is limited and scarce in developing countries such as Botswana. Most of literature on SMEs focuses on factors that contribute to SME survival such as financing, rather than a greater understanding of the growth process and the achievement of sustainable competitive advantage (Storey, 1994). As such, this study seeks to investigate the extent of strategic planning by SMEs and whether the aspect is one of the main contributors to the poor performance or demise of SMEs.

Several researches (e.g. Wang et al., 2007; Veskaisri et al., 2007; Ghobadian and O'Regan, 2002) emphasize that the field of small business is close to entrepreneurship, as the latter recognises the importance of the manager, who is very often the owner. Studies such Gunther and Menzel (2012), Burton et al. (2012) and Temtime and Pansiri (2006) focused solely on owner manager characteristics and how they impact on strategy. The generalisation of these studies is limited as owner manager characteristics vary from firm to firm. Looking into owner-managers role in strategic planning as well as considering other factors that may affect strategy formulation will help us to better understand the concept, which is what the current study has incorporated.

Again, a number of studies (e.g. Ghobadian and O’Regan, 2002; Pemberton and Stonehouse, 2002 and Gunther and Menzel, 2012) concentrated on specific industry sectors which reduces the potential to derive generalizable inferences. It is highly likely that the responses are influenced by the type of industry the firm operates in and so would the analysis. To overcome this limitation, this study considers a multi-sectoral approach which would be beneficial to SMEs across all industries as SMEs can evaluate and use the results as a self -monitoring instrument to improve on their deficiencies. For example, Strategic management in a construction industry may be driven by different factors that are not present in the service or manufacturing industry to mention a few. It would also be interesting to examine whether there are differences in degree of strategic planning with regard to industry affiliation, and therefore this study will look across all sectors.

On another note, some studies such as Adendorff et al. (2011), Sharma (2011), and Polatoglu (2007) are limited to a single case study. The dividing line between operational and strategic planning might become less visible when different types of companies are examined. Depending on the company's nature of operations, it can be argued that some companies need to plan less strategically because they are more flexible and can adapt much faster to changes in their immediate environment. As such, the current study explores a number of companies as opposed to focusing on a single case study to get insights from different positions.

Several studies in strategic planning were conducted in the developed world. For example in the UK (Falshaw et al., 2006; Dyson et al., 2005; Ghobadian and O' Regan, 2002; Pemberton and Stonehouse, 2002), Germany (Gunther and Menzel, 2012), Turkey (Polatoglu, 2007), Slovenia (Antoncic and Skrt, 2004), Austria (Kraus et al., 2007), Greece (Salavouetal, 2004). However the results of these studies are of less significance and may not apply in developing countries because of the differences in political, economic and social and social differences of the developed and developing world. For instance, the geographic areas where the studies were conducted are characterised by mature technologies and industries, therefore the results cannot be extended to other countries with immature technological advances and industries such as Botswana. This study therefore contributes to the limited literature on strategic planning by SMEs in developing countries that have the same environment as Botswana.

\subsection{Theoretical Framework}

In an endeavour to investigate strategic planning by SMEs in Botswana, we employed reputation and resource based theories to explain the relationship(s) between variables under investigation.

According to Gaultier-Gaillard et al. (2009), reputation refers to the beliefs or opinions held about something. George et al. (2012) refers to reputation as the corporate identity of a firm, representation of the culture, values and goals of a company. These definitions are consistent with Fombrun and Van Riel (1997) who posit that reputation is an external reflection of a company's identity. Corporate reputation is forming moral reputation by observing long-term psychological restraint mechanism, forming intangible resources that can improve operational performance and maintain competitive advantage in the long course of the business by guiding and standardizing corporate systems (Yang and Li, 2007, p.198).

Reputation management is a new and emerging function of corporate communication and is used as strategic tactical 
and managerial tool within organisations (Abdullah, 2009). The theory of reputation states that an organisation enjoys a good reputation when it consistently meets or exceeds the expectations of its stakeholders. Fombrun (1996) affirms that companies that develop policies that reflect their core values and show concern for the environment in which they operate enjoy favourable reputations. Several studies (Adeosun and Ganiyu, 2013; Yang and Li, 2007; Fombrun, 1996 and Weigelt and Camerer, 1988) recognise a firm's reputation as a valuable corporate strategic asset that represents the company's status. According to Adeonsun and Ganiyu (2013), reputation makes the difference between success and failure; it explains why customers choose a firm's products and services over those of its rivals.

Stakeholder expectations are shaped by their beliefs about what a business is and what it does (Freeman, 1984). These beliefs are influenced by how the business presents itself. Stakeholders then measure their actual experience of how the business acts against their expectations. A good reputation is achieved when there is congruence between a business's purpose, its goals and values, its conduct and actions and the experience and expectations of its stakeholders (Gaultier-Gaillard et al., 2009). This is consistent with Carmeli and Tishler (2005, p.13) when they state "stakeholders' perception of the institution is based on the positive reputation that the organisation has and can be more attractive than others." Figure 1, the reputation equation shows the relationship between reputation, experience and expectation.

Reputation $=$ Experience - Expectation

Figure 1. The reputation equation

Source: Gaultier-Gaillard et al. (2009)

According to Figure 1, reputation is the result obtained after deducting expectation from experience. As such reputation theory suggests that managing reputational risk has become a major preoccupation for businesses in every sector. A company with a good reputation is regarded as trustworthy, credible, reliable, and responsible for customers, employees, shareholders and financial markets (Mullerat, 2010). A bad reputation, conversely, can result in a loss of customers, unmotivated employees, shareholder dissatisfaction and ultimately the demise of the business itself (Gaultier-Gaillard et al., 2009). Corporate reputation has been recognised as the most important among the intangible assets and should be considered as a core strategic competence of an organisation (Andrikopoulos and Koronis, 2005). Idowu and Caliyurt (2014) confirm this by saying, "The extensive search for sustainable competitive advantage is no longer restricted to tangible assets but also reached the field of intangible assets".

Reputation theory is drawn on the foundation that reputation components be weighted by decision makers and be used as the basis of decision making and incorporated into shaping organisational change in an effort to formulate a corporate strategy. According to Andrikopoulos and Koronis (2005), the creation and maintenance of corporate reputation refers directly to corporate strategic choices and strategic perspectives of the organisation. It is fundamental to examine issues of corporate reputation as they have become crucial parts of organisational strategy. Roberts and Dowling (2002) posit that corporate reputation is conceptualised as a core organisational value, it is directly related with financial results and the strategic positioning of the organisation. Fombrun and Van Riel (2005) put forward that favourable reputations can generate excess returns for firms by inhibiting the mobility of rivals and also, potential owners rely on the reputation of the firms in making investment decisions.

Adeosun and Ganiyu (2013) advise that the quest for being an exclusive, best and responsive company should drive firms to acknowledging that reputation is an important source of competitive advantage. This explains that image and reputation of an organisation is created from its operations, policies and practices, and further means that corporate reputation cannot be alienated from the general strategic plan of the organisation. Taking from the corporate reputation definition and strategic planning definition, it is irrefutable that the two have a relationship. In the context of strategic management, a firm that is reputation conscious will successfully plan and implement its strategy.

Corporate reputation directly affects the strategic behaviour patterns of a firm and the observable characteristics of the manner in which an organisation performs decision making and the planning function with regard to issues that are of strategic importance to its survival, growth and profitability (Adeonsun and Ganiyu, 2013, p. 220).

This theory is therefore important in explaining the extent to which firms engage in strategic planning activities. It may be expected that firms which value a good reputation and view it as a strategic competence that helps the firm to stay competitive would engage in extensive, formal planning. 
Strategy has been defined as the match an organisation makes between its internal resources and skills and the opportunities and risks created by its external environment (Grant, 1991, p. 114). Resource based theory relates the role of a firm's resources as the foundation for firm's strategy. The theory proposes that the resources and capabilities are a source of direction, and are the starting point of strategy formulation as they give a statement of the firm's identity and purpose. Grant (1991) argues that the use of other attributes such as the firm's external environment to define the firm's purpose does not provide a secure foundation for providing a long term strategy. This is because the external environment can go in a state of unrest, whereas the organisation's resources and capabilities can be much more stable and can define the firms business. Figure 2, a resource based approach to strategy formulation depicts the relationship between organisational resources and strategy formulation.

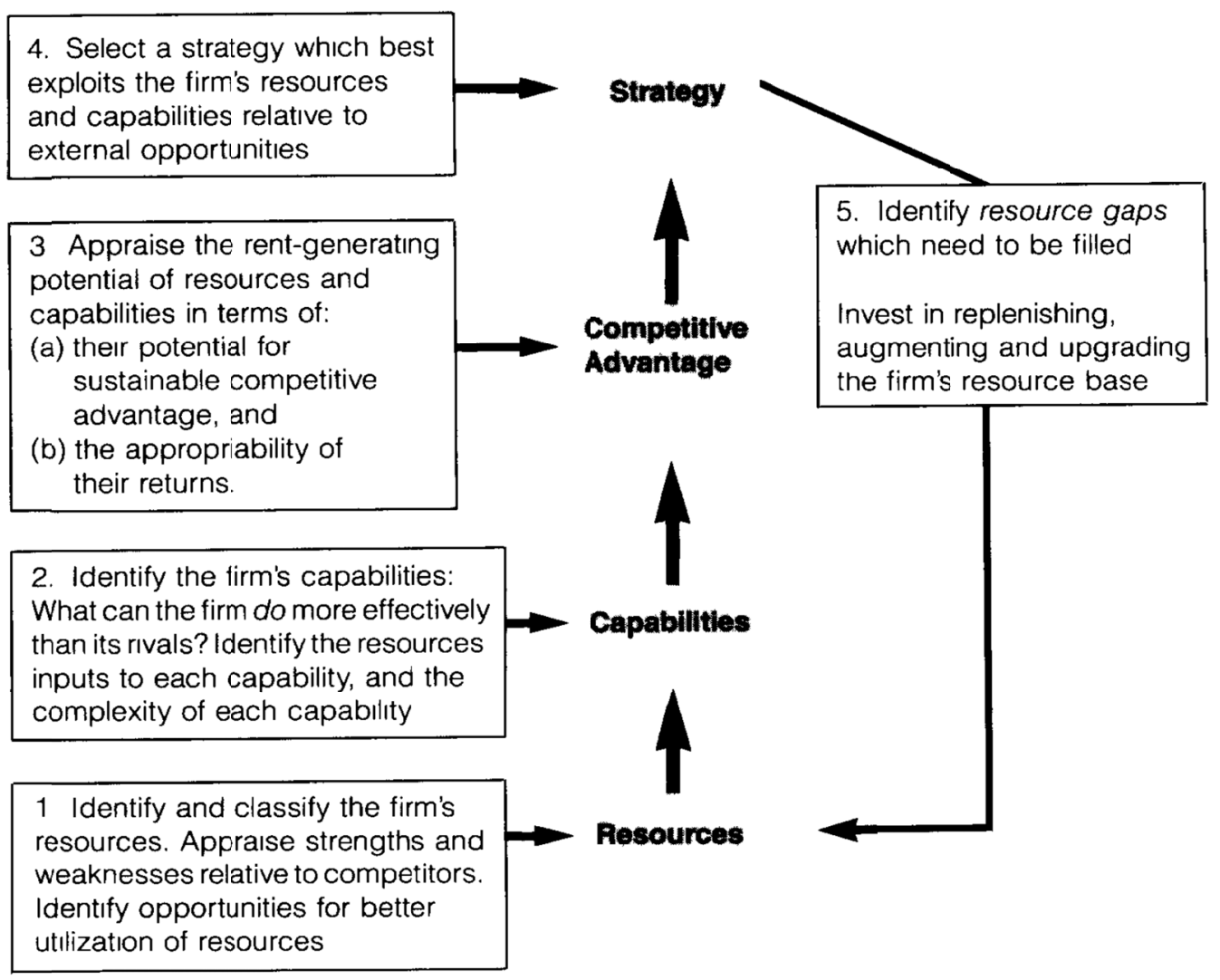

Figure 2. A Resource - based approach to strategy formulation

Source: Grant 1991: The Resource-Based Theory for Competitive Advantage p.115

The resource based approach puts much emphasis on strategic flexibility of firms (Hough et al., 2008). The development of strategic flexibility is important to help firms to cope with the changing market conditions and to also take advantage of existing and new strategic opportunities. The resource based theory is concentrated on the influence of firm resources and capabilities and how the arrangement of these help in explaining why firms differ and how they achieve sustainable competitive advantage. Teece et al. (1997) cited in O'Regan et al. (2006) suggests that strategic management emphasizes the configuration and reconfiguration of resources in order to ensure a 'fit' between the external and internal environments. According to Grant (1991), companies whose strategies have been based upon developing and exploiting clearly defined internal capabilities have been proficient at adjusting to and exploiting external change and have proven to grow successfully.

The primary purpose of the resource based approach to strategy formulation is maximising the returns to market power over time. The critical task is to assess capabilities relative to those of competitors. This theory emphasises 
that the resource and capabilities of a firm are central considerations in formulating strategy and they are the primary resources of the firm's profitability. For a firm, a successful strategy is one, which exploits relative strengths; conversely, failure is often due to strategies, which extend the firm's activities beyond the scope of its activities (Zack, 2009, p. 10). As such, lack of resources in SMEs hinders them to exploit relative strengths, resulting in failure because of strategies which fall short of further extending the scope of a firm's activities.

Therefore the resource based theory explains that firms that best use their resources to create powerful and unique strategies have a competitive advantage. This theory explains that firms need to be aware of their valuable, not easy to replicate, non-substitutable resources and these are categorised in Grant (1991) as financial, physical, human, technological, reputational and organisational. Habbershon and Williams (1999) highlight that there is a development in focusing on the firms internal attributes as a source of advantage. These are the starting point for strategy formulation (Grant, 1991, p. 116) and will determine the extent of planning in an organization. Figure 3, independent, dependent variables \& attributes based research theories, presents a model for this study.

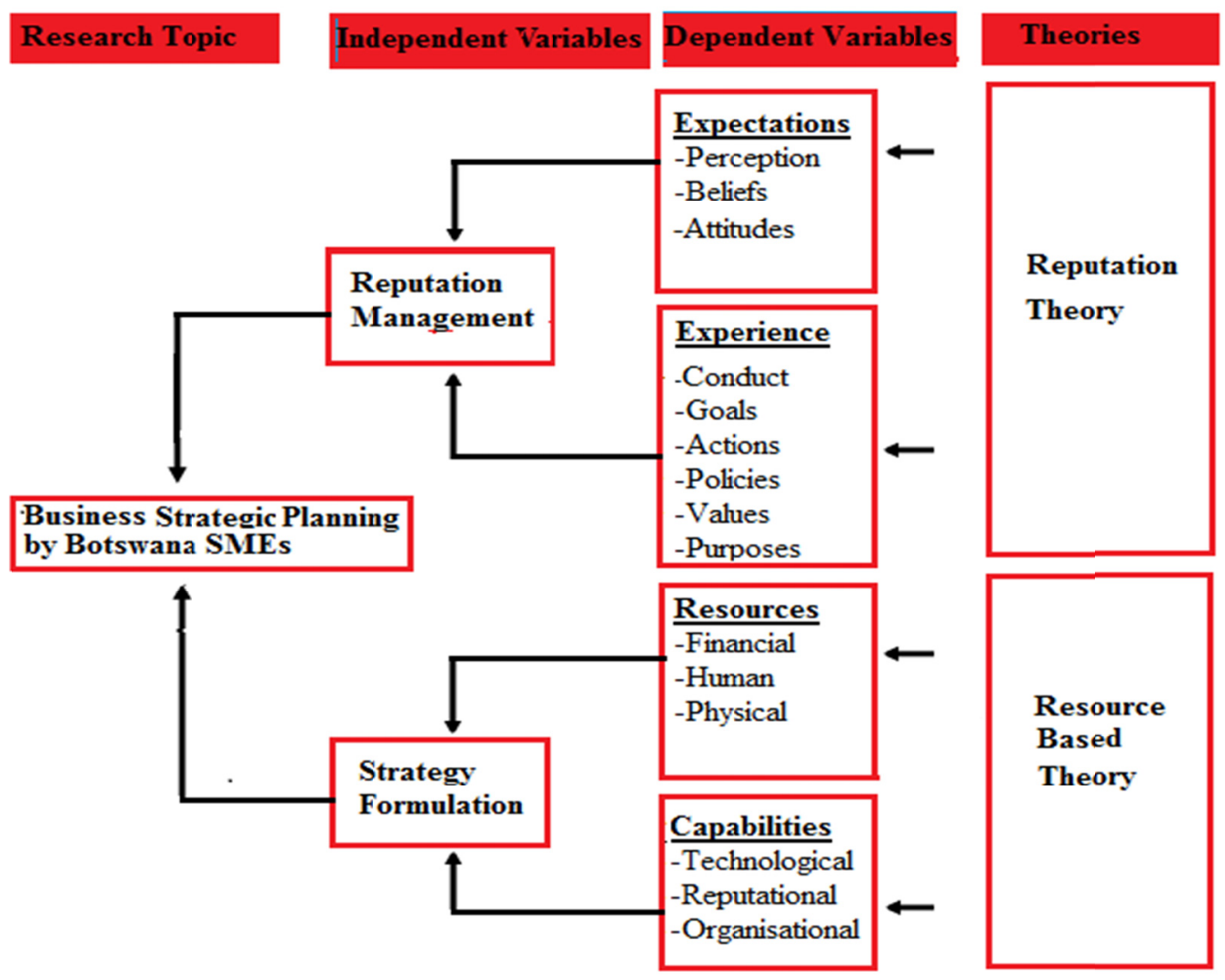

Figure 3. Independent, dependent variables \& attributes based research theories

\section{Research Design \& Methodology}

This study adopted a mixed method approach. Creswell (2006, p. 510) defines the mixed method design as a procedure for collecting, analysing and mixing both quantitative and qualitative data in a single study to answer the research questions. The researchers' choice of a mixed method approach was influenced by its central premise that the use of quantitative and qualitative approaches in combination provides a better understanding of research questions than either approach alone, as argued by Cronholm and Hjalmarsson (2011). Bulsara (n.d.) purports that a mixed method approach answers questions from a number of perspectives and it ensures that there are no gaps to the data collected. According to Driscoll et al. (2007), the qualitative data provides a deep understanding of responses as it allows the respondent to express themselves in detail without being constrained by predetermined responses. This was particularly useful when trying to discern the perception of SME managers on strategic planning. On the other hand, quantitative data facilitated statistical analysis and allowed detailed assessment of patterns of responses when determining the extent of planning by SMEs as well as pooling together the challenges they face, thereby allowing a 
development of a generalizable set of findings. According to Pole (2007), using both qualitative and quantitative allows the researcher to address the theoretical perspective at different levels as the combination helps in overcoming the weakness of a single design especially when dealing with a composite concept like strategy. In contrast with most previous studies (Dubihlela and Sandada, 2014; Kee-Luen et al., 2013; Olawale and Garwe, 2010) that used the quantitative approach, the mixed method approach was considered useful for this study. This approach was deemed appropriate for this study as the aim was not to look into the extent of strategic planning only but also to understand perceptions of owner/managers which cannot be gathered from quantitative data.

\section{Population and Sampling Procedures}

Target population for the study were SME owners/or managers. Owners are individuals or groups of individuals who own the business and managers are those individuals who do not own the business but are responsible for the day to day running of the business such as chief executive officers, managing directors, general managers, and other senior executives. These are directly linked to business strategic decisions of the firms, hence were found to be in a better position to answer any questions regarding the firm's business strategy (Sandada et al., 2014 \&Burton et al., 2012). According to Statistics Botswana SME register the SMEs in Botswana are categorised as illustrated in Table 2, summary of sample selection procedure, below.

Table 2. Summary of sample selection procedure

\begin{tabular}{clr}
\hline Composition of all listed firms/Population & \\
\hline CODE & HEADING & 3 \\
$\mathbf{1}$ & Central Government & 43 \\
$\mathbf{2}$ & Local Government & 139 \\
$\mathbf{3}$ & Parastatals & 4,979 \\
$\mathbf{4}$ & Private Registered & 490 \\
$\mathbf{5}$ & Private Unregistered & 1,086 \\
$\mathbf{6}$ & Multi-establishments & 4,087 \\
$\mathbf{9}$ & Not known & $\mathbf{1 0 , 8 2 8}$ \\
\hline
\end{tabular}

\subsection{Sampling Procedures}

To select a sample for this study, the researchers used random sampling and non-random sampling to obtain a sample population of SMEs in Botswana. Yu and Teddie (2007) describe random sampling or probability sampling as mainly used for establishing an empirical and factual dimension of the population. Onwuegbuzie and Collinsa (2007) also explain non-random or non-probability as an analytical generalization which enables the study to obtain knowledge on key constructs like beliefs, attitudes, perceptions and behaviour of population sample under study.

Random and non-random sampling approaches were found suitable in the study because there is need to generate knowledge, which could be statistical generalized about adoption and implementation of strategic plans by SMEs in Botswana. Yu and Teddie (2007) define convenience sampling as a category of non-random sampling and it is used to filter sample population whose data is complete, accessible and also available. Non-random sampling technique was used by the study to accommodate Botswana SMEs who are conveniently available, willing and accessible to participate in the study. Analysis of the SME population sampled in Table 3; Conveniently Samples Population of Botswana SMEs, reveals that some SME organizations are not completely documented. For instance some SMEs do not have the following key details; institutional type, correct contact details and some addresses were outdated. In view of this, these organizations are removed from the population as they might have tendencies to distort analytic and statistical generalizability of the research results. This observation is also complemented by Kazerooni (2001), who comments the entire population cannot be studied as it is not always readily accessible and incomplete and therefore only representative individuals are selected to provide insights into the entire population under study. As such, this study considered private registered firms only. The study also excluded micro firms (those who had less than 6 employees), because the study focuses on small and medium enterprises only. Firms located in other areas outside Gaborone were also excluded because of cost and time considerations. The conveniently sampled population is indicated in Table 3, conveniently sampled population of Botswana SMEs. 
Table 3. Conveniently sampled population of Botswana SMEs

\begin{tabular}{lcr}
\hline Total Population & $\mathbf{1 0 8 2 8}$ \\
\hline Less & & \\
$\begin{array}{l}\text { All institutional types except } \\
\text { private registered firms }\end{array}$ & 5849 & \\
$\begin{array}{l}\text { Employment size }>\mathbf{2} \text { and } \\
<\mathbf{2 5 0}\end{array}$ & 4572 & \\
\hline Location: Not in Gaborone & 121 & 10542 \\
\hline Firms available for sampling & & 286 \\
\hline
\end{tabular}

Using convenience sampling allowed comparison with other similar previous studies (Sandada, 2015, Nyamwanza \& Mavhiki, 2014 and Mosoti \& Kamau, 2014) that adopted the same technique.

The final population that was available for sampling was 286 firms. From this population, stratified random sampling was used to draw the final sample to collect data to answer all research questions. Stratified random sampling is any approach that is used to select or divide research population into sub-sections comprising groups that are relatively homogenous with respect to one or more characteristics (Onwuegbuzie and Collinsa, 2007). In this research we have selected SMEs which are found to offer services or products in key categories i.e. services, agri-business, retail and construction industries to form the strata. Ten (10) firms were then randomly selected from each strata forming a sample of 50 firms. A summary detailing the response rate per industry is presented in Table 4, stratified sampled population of Botswana SMEs.

Table 4. Stratified sampled population of Botswana SMEs

\begin{tabular}{lcc}
\hline Industry & $\begin{array}{l}\text { Sample in each } \\
\text { industry }\end{array}$ & Reponses \\
\hline Services & 10 & 6 \\
\hline Agri-Culture & 10 & 8 \\
Construction & 10 & 7 \\
\hline Manufacturing & 10 & 7 \\
\hline Retail & 10 & 7 \\
Missing & & 1 \\
Total & 50 & 36 \\
\hline
\end{tabular}

The subjects of this study were 50 small and medium sized businesses in Botswana. However, only 36 honoured their appointments, giving a response rate of $72 \%$. The sample was made up of private registered companies and their employment size ranging between 6 and 250 employees.

\subsection{Data Collection and Instrument Used}

Target respondents for the study were SME owners/or managers in Gaborone. Owners are individuals or groups of individuals who own the business and managers are those individuals who do not own the business but are responsible for the day to day running of the business such as chief executive officers, managing directors, general managers, and other senior executives. These are directly linked to strategic decisions of the firms hence were found to be in a better position to answer any questions regarding the firm's strategy (Sandada et al., 2014 \& Burton et al., 2012).

In order to collect data, appointments were requested with senior management or owners through telephone or 
walk-ins. Some respondents preferred to have a look at the interview guide prior to the interview. As such, the interview guide was emailed a day before the interview following a reminder about the interview. Interviews were planned with each participant in order to provide more in-depth data collection and were scheduled to last for 25 minutes maximum time. A recorder was used to record the interviews in addition to notes and memos. The interviews were transcribed after the interviews. None-verbal cues were also observed during the interview as these can help complement evaluation of the respondent's view. Respondents were asked for their preferred times and venues and the interviewer followed those. All respondents preferred to be interviewed at their place of work. In cases where appointments did not materialise a new appointment was requested. The goal was to interview approximately 50 participants who hold senior position(s) and from SMEs in different industries to have various perspectives across all industries. This method of data collection provided reliable and comparable qualitative data as proven by other preceding studies (Gunther and Menzel, 2012 and Adendorff et al., 2011).

A structured and semi-structured interview guide was used to collect the data necessary to answer the research questions. The structured interview questionnaire and the semi structured interview guide were combined in one instrument divided into four sections. Section A collected the demographic information, section B collected information on strategic formulation and activities whereas section $\mathrm{C}$ concentrated on barriers to strategic planning. The semi-structured interview guide which was named section D collected data that allowed respondents to express their thoughts and position. See Appendix 1; Interview Questionnaire.

The structured interview is based on structured, closed-ended questions. It provides respondents with relevant, meaningful and appropriate response categories to choose from. According to Cohen and Crabtree (2006), structured interviews allow collection of consistent data that can be compared across a number of respondents.

The structured questions were designed to gather quantitative data that is required to evaluate the planning activities of SMEs. Most respondents preferred to fill the demographic section by themselves and follow the interviewer's lead for the rest of the questions. The use of quantitative data allowed the researcher to reveal the pattern and degree of planning among SMEs in Botswana. This was also useful in collecting data pertaining to the barriers in adopting strategic planning activities.

The semi-structured interview involved a series of open ended questions based on the areas that the research covered. According to Newton (2010), the questions were designed such that they define the topic under investigation but also provide an opportunity for both the interviewer and interviewee to discuss some topics in more detail. A semi-structured interview was also considered as it allows the interviewer to prompt to encourage the interviewee to give details should they find the questions challenging or give brief response. Semi- structured interview guide provides a clear set of instructions for interviewers and can provide reliable, comparable, qualitative data (Cohen and Crabtree, 2006). This instrument aided in collecting qualitative data that allowed in-depth review of the strategic planning concept. This was particularly useful for the second research question as it gathers views, opinions, beliefs, and attitudes that build the perception of owner/managers regarding the importance of strategic planning.

We self-constructed most of the research questions and adopted some questions from relevant previous studies (e.g. Gunther and Menzel, 2012; Pemberton \& Stonehouse, 2002 and Ghobadian and O'Regan, 2002).

\subsection{Data Analysis}

Descriptive and inferential statistics was used to analyse quantitative data. Data analysis consists of several activities such as examining the survey interviews for correctness and completeness, coding and keying in data into a database and performing an analysis of descriptive responses. After coding the questionnaire responses, analysis was done using the Statistical Package for Social Sciences (SPSS) for quantitative data. Descriptive statistics was used to analyse demographic data. Quantitative data was presented statistically through the use of graphs, tables and charts for ease of understanding and analysis. Cross tabulations and chi-square goodness of fit test were done to analyse the relationship between firm variables and strategic planning adoption.

In order to analyse qualitative data collected through semi-structured interviews, content analysis was employed. Marying (2000) defines content analysis as a systematic analysis of text. According to Yang and Miller (2008) it is a technique where underlying meanings and ideas are revealed through analyzing patterns of the text. Babbie (1999) states that with this method, the researcher creates a coding system and text is coded basing on this system in order to make observations about the message conveyed. According to Elo and Kyngas (2008) content analysis includes selecting a set of codes to apply to the unit of analysis. This involves identifying patterns and common phrases.

The interviews were transcribed, common themes or issues were identified within responses, these were used to form categories, followed by a count of the frequency of the theme. This was done for each question and followed by 
interpretation of context. This method of analysis proved reliable as it was applied by other preceding studies (Mlanya, 2015 and Chiloane-Tsoka and Boya, 2014). We used Stemler (2001) word frequency count to analyse qualitative data. According to the Stemler (2001), the assumption made is that the words that are mentioned most often reflect the greatest concern among respondents. Marying (2000) states that when used properly, content analysis is a systematic, replicable technique for compressing many words of text into fewer content categories. It is also useful for examining trends and patterns in documents and allows inferences to be made (Stemler, 2001). According to Hsieh and Shannon (2005), there are three approaches to content analysis: conventional, directive and summative. In conventional content analysis, coding categories are derived directly from the text data. This approach was adopted in this study with a directed approach; analysis starts with a theory or relevant research findings as guidance for initial codes. A summative content analysis involves counting and comparisons, usually of keywords or content, followed by the interpretation of the underlying context. A conventional content analysis together with a directed approach was adopted for this study. Categories of data were derived from the responses and these were in accordance with the theoretical framework.

\section{Discussion \& Findings}

\subsection{Descriptive Statistics}

This section provides selected demographical information of the 36 participating respondents. The respondents were asked to indicate their gender; the results are shown in Figure 4, respondents' gender presents demographic results on gender:

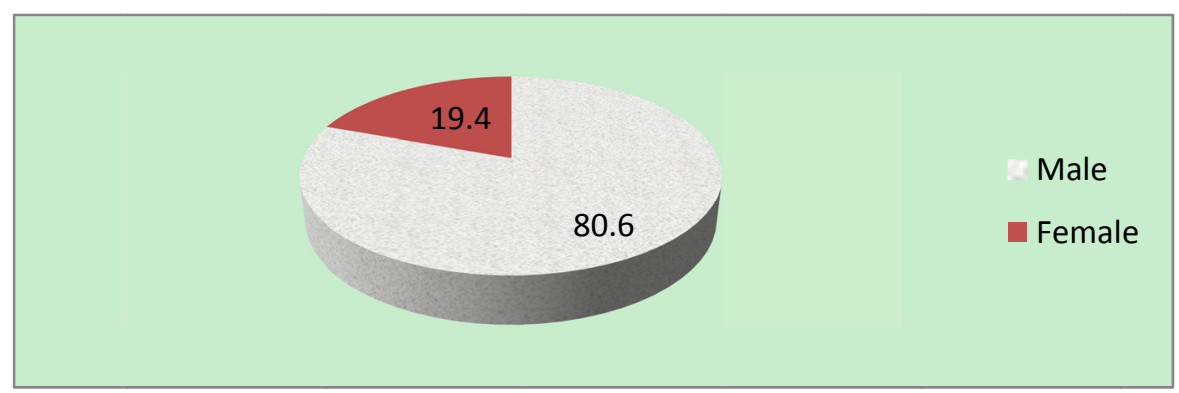

Figure 4. Respondents' gender

The distribution of males to females in the study as depicted by figure 4 shows that the study is not balanced in terms of gender. There are more males as compared to females. About $80.6 \%$ of the respondents were males and the remaining 19.4 were females and this may be an indication that males dominate significantly in SME management in Botswana.

Figure 5, age of respondents presents descriptive statistics with regard to age of respondents.

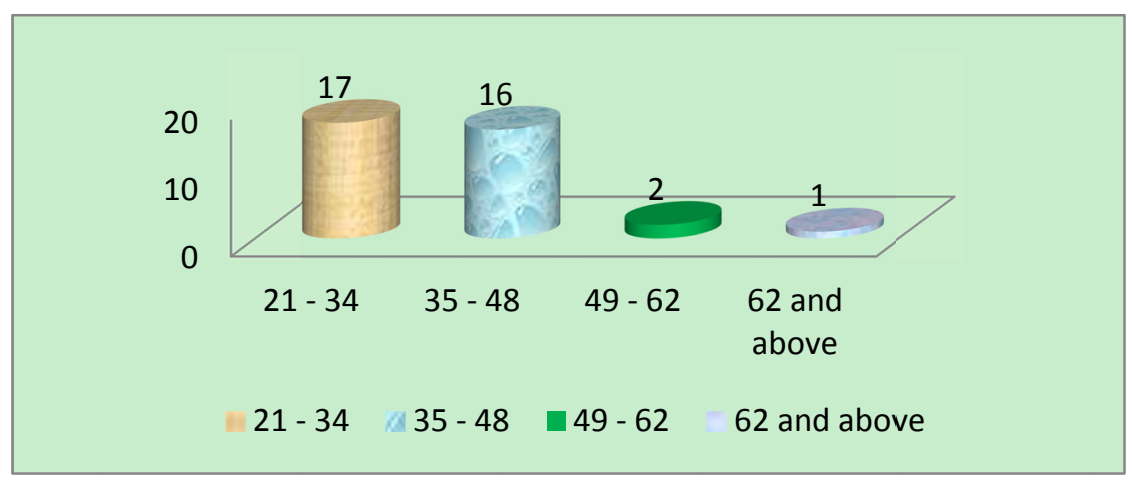

Figure 5. Age of respondents

Figure 5 indicates that most small and medium enterprises in Botswana are run by managers in the young adult stage, which is between 21 and 48. As per results from figure 2, 92\% (33 out of 36) of respondents belong to the age group of 21 to 48 . 
Figure 6, level of education, presents descriptive statistics on the level of education of SME respondents. Results from figure 6 indicate that most SME owner managers are young adults who have undergone some form of training. As depicted by the level of education of respondents, it may be expected that SMEs that are managed by people with some form of training be engaged in formal strategic planning. These results are different from what is expected and the work of Singh et al. (2008), who argues that the success of small firms is attributed to the managerial skills, training, and education of the owner manager. Although this is the case, it implies that even if there is some form of training, this training may not be in business management. This affirms Kraus et al. (2007), who highlight that it is important for SME owner managers to have the capability to run a business in order for the firm to perform well. Kraus et al. (2007) argue that SME management often suffers from an insufficient business-related knowledge base that SME owner managers possess. In essence, "the degree of an entrepreneur's strategic orientation thus seems to be a key factor for the strategic focus of the enterprise", (Mazzarol, 2003, p 8). This may account for why there is little usage of strategic planning tools. These tools are used by a small number and are used on an irregular basis.

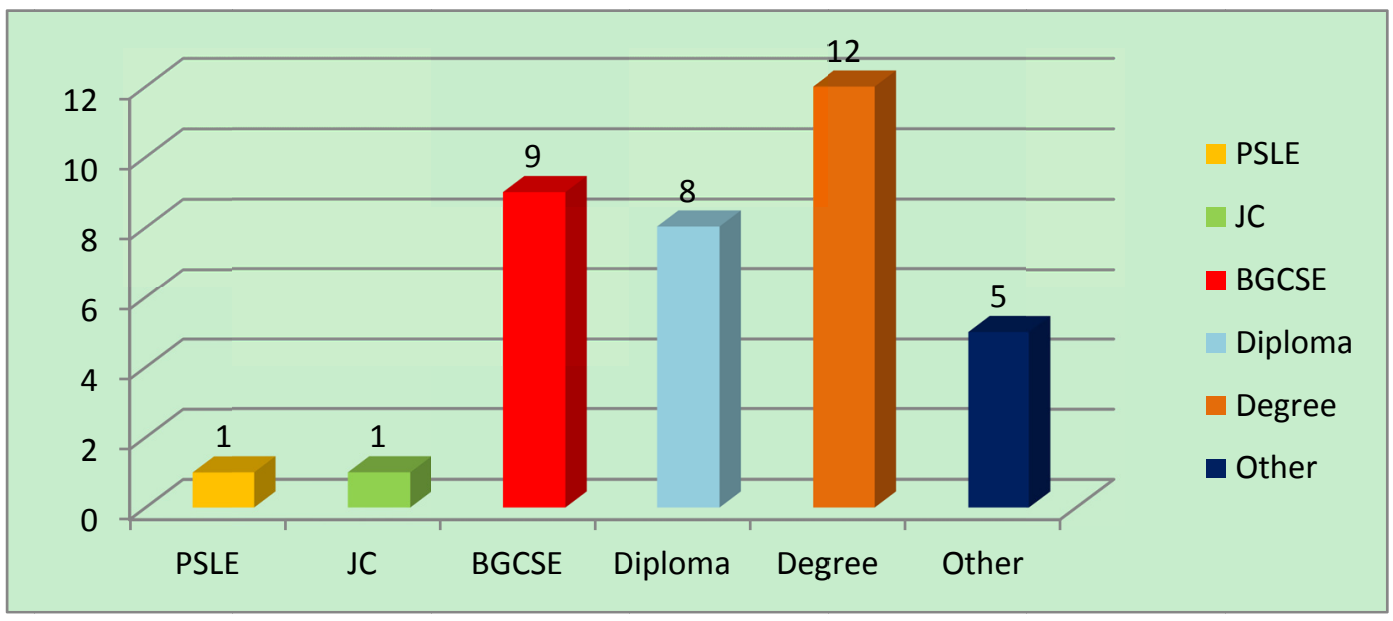

Figure 6. Level of education

Figure 6 also reveals that most SME owner/managers generally hold some educational qualifications. The category "other" shows some professional qualifications in terms of other professional certifications. Majority (12) hold a degree followed by 9 holding Botswana General Certificate of Secondary Education (BGCSE) and 8 respondents who hold a diploma certificate. Only two respondents had the lowest qualifications e.g. Primary School Leaving Examination Certificate (PSLE) and a Junior Certificate respectively. Overall the results indicate that the majority of SME owner/managers have undergone some formal training and it may be expected that they are aware of and engage in business strategic planning.

SMEs were also analysed in terms of number of employees Table 5, number of employees.

Table 5. Number of employees

\begin{tabular}{ccc}
\hline Number of Employees & Frequency & Percent \\
\hline $6-15$ & 18 & 50.0 \\
$16-24$ & 6 & 16.7 \\
$25-49$ & 8 & 22.2 \\
$50-99$ & 4 & 11.1 \\
Total & $\mathbf{3 6}$ & $\mathbf{1 0 0 . 0}$ \\
\hline
\end{tabular}

According to Table 5, most firms are operating as small enterprises with less than 25 employees. About $67 \%$ of the SMEs have less than 25 workers while about $22 \%$ of the SMEs have between 25 and 49 employees and about $11 \%$ 
have between 50 and 99 employees. The respondents were also asked to state the firm's annual turnover; the results are presented in Table 6, annual turnover.

Table 6. Annual turnover

\begin{tabular}{ccc}
\hline Annual Turnover & Frequency & Percent \\
$60000-499000$ & 10 & 27.8 \\
$500000-1500000$ & 9 & 25.0 \\
$1600000-2500000$ & 6 & 16.7 \\
$2600000-5000000$ & 7 & 19.4 \\
Over 5 000000 & 4 & 11.1 \\
Total & $\mathbf{3 6}$ & $\mathbf{1 0 0 . 0}$ \\
\hline
\end{tabular}

The distribution of annual turnovers is positively skewed. Many SMEs have a turnover of less than P2 500000 (two million five hundred Pula) and the numbers decrease as turnover increases to more than P5 million. The results imply that most firms are operating as small enterprises.

Respondents were also asked to indicate the number of years that the firm has been in operation, the results are shown in Figure 7, age of the firm.

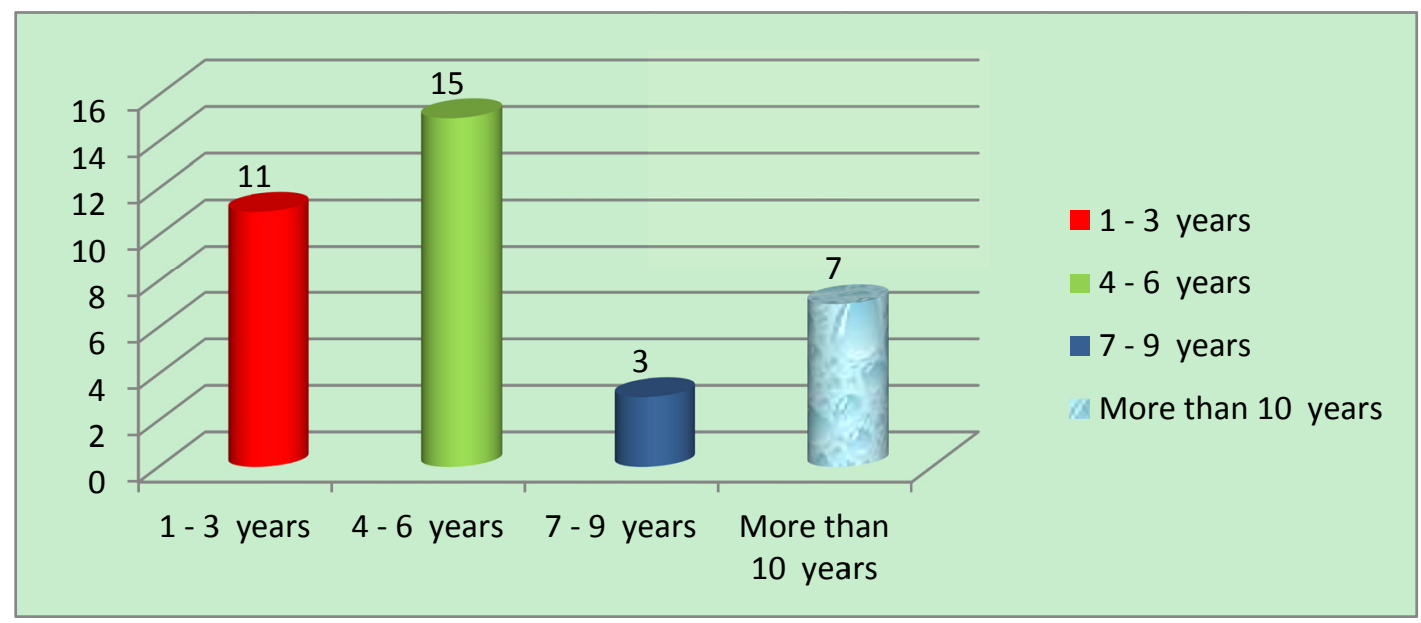

Figure 7. Age of the firm

The results of the study reveal that the majority of the firms are still in their infancy, with about 15 of the SMEs having 4 to 6 years in operation, followed by 1 to 3 years (11 out of 36). Only 3 firms indicated to have been in operation for about 7 to 9 years and 7 firms have been operating for more than 10 years.

SMEs were also analysed in terms of industry type, Table 7, type of industry.

Table 7. Type of industry

\begin{tabular}{|ccc}
\hline Industry Type & Frequency & Percent \\
\hline Services & 6 & 16.7 \\
Agri - business & 8 & 22.2 \\
Construction & 7 & 19.4 \\
Manufacturing & 7 & 19.4 \\
Retail & 7 & 19.4 \\
No Response & 1 & 2.8 \\
Total & $\mathbf{3 6}$ & $\mathbf{1 0 0 . 0}$ \\
\hline
\end{tabular}


There is almost a balance in the distribution of the type of industry in the sample. All the five industry sectors studied were almost equally represented. From the observed results the types of industry seem to have equal chances of occurring with Agri- business having a slightly higher chance, services having a slightly lower chance as compared to the others which have equal opportunities.

In order to test the relationship between age of respondents and age of firm a cross tabulated and chi-square goodness of fit procedure was performed. The results are summarised in Table 8, cross tabulation of age of respondent and age of the firm.

Table 8. Cross tabulation of age of respondents and age of the firm

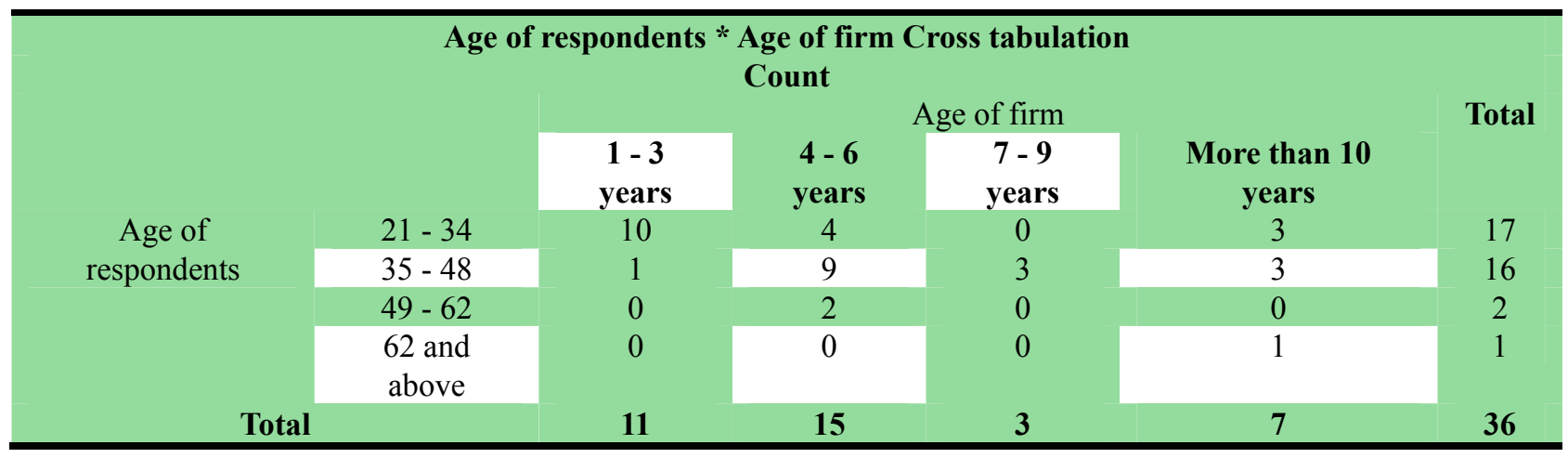

The cross tabulated and Chi-Square goodness of fit (Table 9, Chi-Square test of age of respondents \& age of the firm) shows that there is a significant relationship between age of respondents with age of the firm as the $p$ value is .01 which is less than the required significance of $p<.05$. Table 9; Chi-Square Test of Age of Respondents and Age of the Firm clearly shows younger respondents work for or own firms with a few years in operation.

Table 9. Chi-Square test of age of respondents and age of the firm

\begin{tabular}{l|r|r|c}
\hline \multicolumn{4}{c}{ Chi-Square Tests } \\
& Value & df & Asymp. Sig. (2-sided) \\
& & & \\
\hline Pearson Chi-Square & $20.173^{\mathrm{a}}$ & 9 & .017 \\
\hline Likelihood Ratio & 21.599 & 9 & .010 \\
Linear-by-Linear Association & 4.820 & 1 & .028 \\
N of Valid Cases & $\mathbf{3 6}$ & & \\
\hline
\end{tabular}

Generally this study suggests that SMEs in Botswana are owned or managed by more males compared to females. Most owner/managers of SMEs are young adults of ages 21 to 34years. The findings of the study also imply that SME owner/managers are educated or have undergone some form of training. The study also reveals that the SME industry is dominated by small firms with a low number of employees (less than 24 employees) and a low annual turnover (1 million five hundred pula). The findings also imply that most SMEs have been in operation for about 4 to 6 years.

\section{Strategic Planning in SMEs in Botswana}

Generally, the findings of the study indicate that a small number of SMEs in Botswana engage in strategic planning activities and the level of engagement is limited. For instance, only $44.4 \%$ (Table 10 . Availability of vision, mission and long term objectives) of the respondents had all three components of strategic planning e.g. vision and mission and long term objectives while $55.6 \%$ either had one or two of the components. Almost $19 \%$ of the respondents had none of the vision, mission, nor long term objectives. According to the results of the study, $22 \%$ of sample SMEs had only one of the three components of strategic planning with only one firm having a mission only. 
Table 10. Availability of vision, mission and long term objectives

\begin{tabular}{|l|c|c|}
\hline & Frequency & Percent \\
\hline Vision & 3 & 8.3 \\
\hline Mission & 1 & 2.8 \\
\hline Long term Objectives & 4 & 11.1 \\
\hline All of the above & 16 & 44.4 \\
\hline 1 and 2 & 2 & 5.6 \\
\hline 1 and 3 & 3 & 8.3 \\
\hline none of the above & 7 & 19.4 \\
\hline \multicolumn{1}{|c|}{ Total } & $\mathbf{3 6}$ & $\mathbf{1 0 0 . 0}$ \\
\hline
\end{tabular}

The findings of this study are in accordance with results from other studies (Piest, 1994; Ghobadian and O'Regan, 2002; Arasa and Ókonyo, 2012 and Antoncic and Skrt, 2004) that state that strategic planning efforts do exist among SMEs but to a limited degree. It may be concluded that SMEs tend to have the mission and vision and long term objectives documented in their profiles just for formality or to follow the trend. The contribution of these components to the day to day operations of the business is overlooked. George et al. (2012) posit that the mission, vision and objectives set out a company's long-term goals and aspirations clearly and briefly and may be used to inspire and motivate the company's workforce by providing a picture of where the organization is heading and form an essential part of the strategic management process.

According to Ling and Wang (2007) reputation management is ensuring that a firm's purpose, values, goals are reflected in their policies and actions so as to ensure that the stakeholders' expectations are met. Therefore the results of the study suggest that SMEs in Botswana are not reputation conscious, as most of them do not have formal strategies in place and those that do, do not incorporate them in their daily activities. Ling and Wang (2007) further establish that reputation is the foundation of successful strategy implementation, meaning a firm that is not reputation conscious will not successfully plan and implement its strategy, which is the case with SMEs in Botswana.

These findings are also consistent with Balasundaram (2009) who states that strategic planning in SMEs is informal, unstructured and irregular. Most respondents as gathered from the interviews have strategies at the top of their head but have not documented them. The lack of documentation may contribute to why they don't follow these plans. Ghobadian \& O'Regan (2002) and Stewart (2002), cited in Veskaisri et al. (2007) also affirm that the formality of strategic planning includes the development, implementation as well as a continued update of a documented business plan. The findings of this study are not any different from the existing literature, as the findings reveal the same pattern, the presence of strategic components but no action plan on how to achieve them and no formality or documentation of the same. Therefore this implies that SMEs in Botswana engage in strategic planning to a small extent and planning is informal.

\section{Perceptions of SME owner/managers regarding the importance of strategic planning in Botswana}

Results of this study indicate that only $17 \%$ of the sampled SMEs incorporate their game plan in their daily activities, while $25 \%$ approximately incorporated the plans. A surprising $56 \%$ of the sampled firms do not incorporate their plan in their daily activities.

Table 11. Incorporation of strategic plan in daily activities

\begin{tabular}{llcc}
\hline \multicolumn{3}{l}{ Does your organization incorporate } & \multicolumn{3}{c}{ this } & \multicolumn{3}{c}{ in } & daily activities? \\
\hline \multirow{2}{*}{ Valid } & Very precisely & Frequency & Percent \\
& Approximately & 6 & 16.7 \\
& No & 9 & 25 \\
& Total & 20 & 55.6 \\
\multirow{4}{*}{ Missing } & System & 35 & 97.2 \\
Total & & 1 & 2.8 \\
\hline
\end{tabular}


Having a strategy and not following it means that little value is attached to the strategy or it does not work. Also, if the owner/manager believes in running the business reactively on a day to day basis using intuition and experience, they may see no point in following a plan. This may be an indication that SMEs in Botswana do not value strategic planning to some extent. This contradicts the reputation theory that states that a good reputation is achieved when there is congruence between a business's purpose, which is its mission, its goals and values and its activities. From the results, a number of firms have a vision, mission and goals but do not reflect those by incorporating them in their activities.

Almost all the respondents agree that it is very important to have strategies to achieve set objectives. Some of the responses were as follows:

"A strategic plan helps you to know the direction of the business i.e. it guides operations, to identify challenges and to work out solutions to solve the problems." (Respondent 21).

"A strategic plan gives information to all concerned stakeholders of what is to be achieved and how it is to be done, in other words it enhances company performance and it helps in decision making" (Respondent 36).

“...the plan helps to monitor and contain setbacks and it also helps to measure time lines for set plans or goals." (Respondent 28).

Some respondents pointed out that they don't follow laid out plans. Others pointed that they don't know about planning and they don't have any objectives, this suggests that they have no value for planning. One went to the extent of stating that;

"planning is waste time, we want money and that is what we look for," (Respondent 20).

Others stated that, a strategic plan depends on the manager or owner who has personal interests and they do everything to protect their interest, meaning that the individual (e.g. Respondent 19) dictates the value of strategic planning.

Although respondents strongly supported the need for a strategy (e.g. 53\% of respondents versus 47\%), there was no evidence of such value from the practical side. For instance very few SMEs have their strategies documented and majority reported that they do not incorporate their strategies in their daily activities. Evidence from the interviews, indicate that respondents have a strategic plan at the top of their head but have not written it down/documented (53\%), while $8 \%$ had it documented and 36\% had no plan at all and 3\% did not respond to this question. This may indicate that the owners/managers of these organizations don't perceive formal strategic planning as essential for the organization. The results of the study may indicate that respondents do not practice what they preach. This is consistent with Pemberton and Stonehouse (2002) who concluded from their findings that low usage of strategic techniques and focus on short term objectives indicates lack of awareness of the need for a longer- term strategy and a lack of belief in the value of the strategic planning. Most respondents expressed that strategy is key to the success of the SMEs. One respondent indicated that:

"Planning enhances performance as you can trace what you are not doing right, it gives direction."(Respondent 35). "Lack of planning makes other things impossible". Another said, "Lack of planning affects competitiveness" (Respondent 36).

These quotations from the interviews suggest that despite their lack of planning, there is some awareness on the importance of strategic planning within SMEs, it may be because of the factors outlined that SMEs do not make strategic plans.

In terms of planning horizon, the results of the study indicate that $16.7 \%$ of the respondents stated that business planning in their organization is for less than one year, $38.9 \%$ between one and two years and $16.7 \%$ between three and four years. In total about $74.3 \%$ of the respondents plan for less than five years, this is considered to be short to medium term planning. Only $8.6 \%$ of the respondents plan for about five to eight years whereas $5.6 \%$ of the respondents plan for more than eight years while $13.9 \%$ said they do not plan at all. The duration of business planning in the observed organizations somehow corresponds to the years of operation of the organizations as most of them are still in their infancy. The findings reveal that the majority of SMEs, about 55.5\% have a planning horizon of 1 to 3 years.

Respondents were also asked to state the tools and techniques that they use for planning. Content analysis of the responses yielded key thematic areas as illustrated in Table 12, tools used in strategic business planning. 
Table 12. Tools used in strategic business planning

\begin{tabular}{|l|c|c|}
\hline \multicolumn{2}{|c|}{ Tools used for formulating business strategic plans } & \\
\hline SWOT & Frequency & Percent \\
\hline Budgets, Financial forecast/Statements & 1 & 2.8 \\
\hline Market Survey/Research & 5 & 13.9 \\
\hline Combination of Tools (2 or more) & 2 & 5.6 \\
\hline No Tools & 7 & 19.4 \\
\hline Total & 21 & 58.3 \\
\hline
\end{tabular}

Table 12 reveals that majority of SMEs do not use strategic planning tools. For instance, $58.3 \%$ stated that they do not use any tools followed by $19.4 \%$ who use tools of various nature. A combination of tools refers to two or more strategic planning tools. The findings also reveal that $13.9 \%$ use financial forecasts or budgets. The SME organizations stated that use of budgets and financial forecast is relatively easy and especially with tools like excel spread sheet for making financial estimates. A few respondents stated that they use SWOT analysis though they did not refer to it as such. SWOT is a situational analysis tool for company leaders that involves assessing strengths, weaknesses, opportunities and threats (Valentin, 2001). They stated they analyse the threats, opportunities and considered their capabilities to act on the threats and take advantage of the available opportunities;

"...we review internal and external forces as well as business opportunities" (Respondent 3).

Although only one respondent singled the use of a SWOT analysis, a few others stated that they use it with a combination of other tools.

A few respondents stated use of market survey or research $(5.2 \%)$ which informs the development of their business strategic plans. SME organizations reported that they use market surveys either in form of research or just observation. The overall responses given by these SMEs indicate that there is little awareness of various planning tools that are available in the business industry and their use in business strategic planning. Strategic planning tools are very important. This implies that SMEs in Botswana have limited knowledge on strategic planning tools.

Respondents were further asked to state how they measure performance to track the success of their plans. The responses were content analysed and results are presented in Table 13, measures of performance by SMEs.

Table 13. Measures of performance by SMEs

\begin{tabular}{lcc}
\hline Performance measures & & \\
\hline & Frequency & Percent \\
\hline Financial performance & 16 & 44.4 \\
\hline Customer growth & 2 & 5.6 \\
\hline Set Milestones/Output & 5 & 13.9 \\
Staff retention & 4 & 11.1 \\
\hline Feedback Review & 3 & 8.3 \\
\hline Combination & 9 & 25.0 \\
\hline
\end{tabular}

The study reveals that $44.4 \%$, which is a significant number of the respondents' measure financial performance to track their success. According to the respondents, financial performance includes profit analysis, acquisition of assets as well as being able to cover the firm's expenses. Respondents reported that they do a financial review for the set targets and compare budgets against actual outcomes. Some respondents, 13.9\% reported that they measure performance by providing small measurable milestones/deliverables and measure success against the set objective. Table 13 also shows that $11.1 \%$ of SMEs considers staff retention as a performance measure. One respondent indicated that staff retention and a growth in the number of employees indicates that they are doing well as a business. Other measures include growth in clientele base as well as feedback review. Some respondents indicated that they use several measures to track success of their plans. About $25 \%$ said they use a combination of factors 
mostly being profits and staff retention, profits and feedback review as well as profits and achievement of milestones. From the responses above it is clear that SMEs employ different performance measures to track the success of their plans. The ability to measure performance is an indication of some element of planning and forms part of strategic management. Overall these findings imply that SMEs in Botswana do engage in strategic planning activities though it is not extensive and is informal.

Empirical evidence shows that in most SMEs, only senior executives and/or owners are involved in strategic planning. For instance $47 \%$ of SMEs indicated that that strategic planning is the prerogative of business owners (e.g. Figure 8, member involvement in strategic planning. In addition about $14 \%$ reported that business owners and chief executives were involved in strategic planning while one firm indicted that senior management is involved in planning and almost $17 \%$ of the SMEs indicated that strategic planning was not applicable to them.

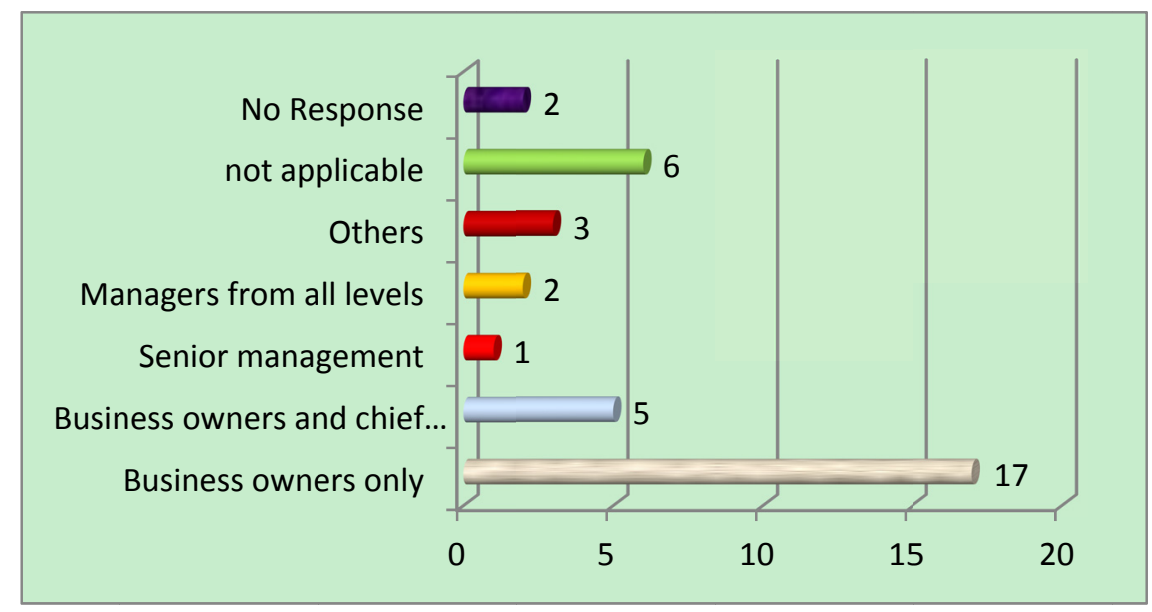

Figure 8. member involvement in strategic planning

The results indicate that only top executives are aware of where they want to take the company, but other employees are in the dark regarding what they are working towards. Wang et al. (2007) argues that reluctance to share strategic plans with employees and external consultants are detrimental to compromise strategic planning in small businesses. Consequently the strategic orientation of small enterprises may be in close relation to the individual's ambition and motivation. This may be influenced by a lot of other factors such as demographics, religion and social issues which is why the strategy that an SME follows tends to be inclined towards the owner manger's motivation of being in business. Some owner/managers view the enterprise as a source of employment therefore growth potentials are not of interest for as long as they get their pay. Some are profit oriented and only concentrate on making profits than the future of the organisation.

\section{Challenges faced by SMEs in Adopting Strategic Planning in Botswana}

Results of this study indicate that there are several factors which impede SMEs from adopting strategic formulation and planning. According to the results, 23 out of $36(64 \%)$ of the respondents selected insufficient knowledge of the planning process, making it the dominating factor, followed by the size of business which was selected by 17 out 36 (47\%) respondents, ranking it second. Traditional-based thinking came third with 7 (19\%) respondents and lack of time came fourth. One respondent mentioned that planning is driven by the managing director so planning is centred on what he wants.

The findings of this study indicate that SMEs are aware of strategic planning and its contribution to SME performance but do not know where to start and how to go about it. The findings conform to the resource based theory that emphasizes that a successful strategy is one which exploits relative strength to extend the firms activities in order to survive the competitive market. Thus lack of capabilities and resources such as skilled personnel hinders these SMEs to exploit their relative strength and as such their strategies will fall short of extending their firms scope. Limited knowledge in strategic planning, size of the business, rejection of external assistance, and fear of radical change are some common challenges that prevent SMEs from engaging in strategic planning activities. Other challenges also exist that may also affect planning in SMEs, however the results suggest that lack of knowledge on the strategic planning process is the greatest hindrance to many SMEs. 


\section{Conclusion}

This study adds to the existing literature on SMEs by specifically investigating strategic planning of these organisations in a developing country. The main findings of the study reveal that strategic planning is limited in SMEs, in Botswana. The study also finds that strategic plans in SMEs in Botswana plans are informal and undocumented. Majority of organisations plan for a year to three years and there is little usage of strategic planning tools with the most common being financial analysis. The study however establishes some factors which prevent SMEs from engaging in strategic planning activities. Lack of knowledge of the planning process is the leading factor affecting planning followed by the size of the business. SMEs felt that since they are mostly a one man business, they are flexible and focus on operational activities instead of the time consuming strategic plans. This suggests that owner managers of SMEs lack business management or entrepreneurial skills that will make them aware of the importance of growth activities such as strategic planning. These findings are in accordance with Ghobadian and O'Regan (2002), who posit that firms which value strategic planning will have a formal strategic planning approach. According to the authors, such firms are more likely to give active consideration to potential barriers than firms using non formal planning. Since SMEs contribute significantly to the economy of the country, it is fundamental that entrepreneurial training and coaching be taken to greater heights to equip SME owner managers with the right skills to enable them to engage in planning activities to ensure survival and growth of the SME sector.

Overall, this study has important implications for the SMEs, the Entrepreneurial development agencies as well as the government of Botswana. Since previous researches have shown that strategic planning benefits SMEs significantly but the findings of this study suggest that SMEs in Botswana engage in Strategic Planning to a small extent. This is an indication that strategic planning is not easy and certain educational platforms need to be established to aid in educating SME owner/managers to plan and successfully implement strategies.

This study has some limitations. For instance, due to time and financial constraints, the study was limited to one part of the country being Gaborone. This limits the generalisation of the results of the study to other parts of the country. The willingness of owner-managers to participate in the interviews was also a challenge. Some would make appointments but never show up and some would cancel. Owner-Managers were also reluctant to give information about their firms as they thought the researchers would give it away especially when asked to record interviews on a tape recorder. As such, researchers had to resort to taking notes.

Future studies should draw a sample of SMEs from across the country to establish if location affects involvement in strategic planning by firms.

\section{References}

Abdullah, Z. (2009). Beyond corporate image: Projecting international reputation management as a new theoretical approach in a transitional country. International Journal of Economics and Management, 3(1), 170-183.

Abor, J. (2007). Debt policy and performance of SMEs: Evidence from Ghana and South African firms. Journal of Risk Finance, 8(4), 364-379.

Abor, J., \& Quartey, P. (2010). Issues in SME development in Ghana and South Africa. International Research Journal of Finance and Economics, 39(6), 215-225.

Adam, F. (2014). Methodological and Epistemic Framework: From Positivism to Post-Positivism. Retrieved February 20, 2016, from www.springer.com

Adendorff, C., Appels, G., \& Botha, B. (2011). Strategic management: An Eastern Cape construction SME case study. ActaStructilia, 18(2), 40-63.

Adeosun, L.P. K., \& Ganiyu, R.A. (2013). Corporate Reputation as a strategic asset. International Journal of Business and Social Science, 4(2), 220-225.

Adèr, H.J. (2008). Advising on Research Methods: A consultant's companion. Huizen, the Netherlands: Johannes van Kessel Publishing, 333-356.

Aigbavboa, C.O., \& Thwala, W.D. (2014). Challenges facing black owned small and medium construction companies: A case study of Nelspruit-Mbombela municipality, South Africa. Journal of Economics and Behavioral Studies, 6(10), 771-778.

Amurle, G., \& Gakure, R. (2013). Strategic planning practices in ICT SMEs in Kenya: What other SMEs can learn. Prime Journal of Social Science, 2(6), 336-349.

Andrikopoulos, A., \& Koronis, E. (2005). Towards a corporate reputation portfolio: Using the Portfolio Theory 
Principles in the Strategic Management of Corporate Reputation Capital. Retrieved January 16, 2015 from http://ssrn.com/abstract=872699

Antoncic, B., \& Skrt, B. (2004). Strategic Planning and small firm growth: An Empirical examination. Managing Global Transitions, 2(2), 107-122.

Arasa, R., \& K'Obonyo, P. (2012). The Relationship between strategic planning and firm performance. International Journal of Humanities and Social Science, 2(22), 201-213.

Aremu, M.A. [Moriam, Adeyemi], Olodo, H.B., \& Aremu M.A.[Mukaila, Ayanda]. (2015). Impact of strategic management on the performance of small and medium scale enterprises (SMEs) in Nigeria. Journal of Sustainable Development in Africa, 17(1), 101-114.

Babbie, E. (1999). The basics of social research (8th ed.). Belmont: Wadsworth Publications.

Babbie, E., \& Mouton, J. (2001). The practice of social research. Oxford University Press Southern Africa, Capetown.

Balasundaram, N. (2009). Incidence of Strategic Planning in Small Business: an Overview. BULETINUL Universităţii Petrol - Gaze din Ploieşti, LX1(3), 11-17.

Barnes, D. (2002).The manufacturing strategy formation process in small and medium sized enterprises. Journal of Small Business and Enterprise Development, 9(2), 130-149.

Beaver, G. (2003). Management and the Small firm. Strategic Change, 12(2), 63-68.

Beck, T., \& Demirguc-Kunt, A. (2006). Small and Medium size entreprises: Access to finance as a growth constraint. Journal of Banking and Finance, 30(11), 2931-2943.

BICA. (2013). Promoting the Growth of Small and Medium Entreprises. African Congress of Accountants. BusinessCase. Retrieved September 2, 2014, from http://acoa13.com

Birley, S., \& Niktari, N. (1995). The failure of owner-managed businesses: The diagnosis of accountants and bankers. Retrieved September 2, 2014, from http://www.opengrey.eu/item/display

Borg, W.R., Gall, J.P., \& Gall, M.D. (2003). Educational Research: An Introduction ( $7^{\text {th }}$ ed.). White Plains. New York. Longman.

Bounds, M., Goldman, G.A., \& Thompson, C. (2012). The Status of Strategic Planning in Small and Medium Enterprises: Priority or Afterthought. The Southern African Journal of Entrepreneurship and Small Business Management, 5(1), 34-53.

Bulsara, C., (n.d.). Using mixed methods approach to enhance and validate your research. Retrieved December 6, 2016 , from https://www.nd.edu.au/downloads/research/ihrr/using_mixed_methods_approach_to_enhance_and_validate_yo ur_research.pdf

Burton, R.M., Hakonsson, D.D., Lauridsen, J.T., \& Obel, B. (2012). Strategy Implementation requires the right executive style: Evidence from Danish SMEs. Long Range Planning, 45(2), 182-208.

Cant, M.C., \& Wild, J. (2013). Establishing the challenges affecting South African SMEs. The International Business and Economics Research Journal, 12(6), 707-716.

Carpenter, R.E., \& Petersen, B.C. (2002). Is the growth of small firms constrained by internal finance? Review of Economics and Statistics, 84(2), 298-309.

Chiarvesio, M., Di Maria, E., \& Micelli, S. (2004). From Local networks of SMEs to virtual districts? Evidence from recent trends in Italy. Research Policy, 33(10), 1509-1528.

Chiloane-Tsoka, E., \& Boya, K.S. (2014). An Exploration of strategic competitiveness of SMMEs: A South African perspective. Problem and Perspectives in Management, 12(4), 347-354.

Chisasa, J., \& Makina, D. (2012).Trend in credit to smallholder farmers in South Africa. The International Business and Economics Research Journal, 11(7), 771-784.

Christodoulou, M. (2009). Confusion over SME size could complicate internal rules. Accountacy Age. Retrieved September 18, 2014, from http://www.accountacyage.com

Cohen, D., \& Crabtree, B. (2006).Qualitative research guidelines project. Retrived December 10, 2015, from http://www.qualres.org/HomeSemi-3629.html 
Cox, B.G. (2010). Research Methods. Encyclopedia of Survey Research Methods.

Creswell, J.W. (2006). Qualitative Enquiry and Research design: Choosing among five Approaches. Sage Publication.

Creswell, J.W. (2013). Research design: Qualitative and quantitative and mixed methods approaches (4 ${ }^{\text {th }}$ ed). Sage Publication. Retrieved January 25, 2016, from http://www.researchgate.net

Cronholm, S., \& Hjalmarsson, A. (2011).Experiences from sequential use of Mixed Methods.The Electronic Journal of Business Research Methods. Retrieved June 20, 2015, from www.ejbrm.com

Crossan, F. (2016). Research philosophy: towards an understanding. Issues in Research, 11(1), 46-55.

Dale, A. (2006). Quality issues with survey research. International Journal of Social Research Methodology, 9(2), $143-158$.

Deakins, D., \& Freel, M. (1998).Entrepreneurial learning and the growth process in SMEs. The learning organisation, 5(3), 144-155.

Derbaliev, S., \& Trpkova, M. (2011). Strategic planning practice in transition economies: Empirical evidence from the Macedonian context. Business and Economic Horizons, 4(1), 27-39.

Driscoll, D.L., Appiah-Yeboah, A., Rupert, D.J., \& Salib P. (2007). Merging Qualitative and Quantitave Data in Mixed Methods Research: How To and Why Not. Ecological and Environmental Anthropology, 3(1), 18-28.

Drucker, P. (2004). Management tasks, responsibilities and practices ( $6^{\text {th }}$ ed.). New Delhi: Allied Publishers.

Dubihlela, J., \& Sandada, M. (2014). Impact of Strategic Planning on Small and Medium-sized Enterprises' (SMEs) Performance: The Role of Employee Participant, Implementation Incentives and Evaluation and Control. Journal of Economics, 5(1), 45-55.

Dyson, R.G., Meadows, M., \& Tapinos, E. (2005). The impact of performance measurement in strategic planning. International Journal of Productivity and Performance Management, 54(5), 370-384.

Elo, S., \& Kyngas, H. (2008). The qualitative content analysis process. Journal of Advanced Nursing, 62(1), 107-115.

Esbio, F., \& Miclat, J.R. (2005). Strategic planning in Education: Making Change Happen ( ${ }^{\text {st }}$ ed.). RBSI. Manila.

Falshaw, J.R., Glaister, K.W., \& Totoglou, E. (2006). Evidence on formal strategic planning and company performance. Management Decision, 44(1), 9-30.

Finnegan, G., Howarth, R., \& Richardson, P. (2004). The Challenges of Growing Small Businesses: Insights from Women Entrepreneurs in Africa. Series on Women's Entrepreneurship Development and Gender Equality, Paper No. 47.

Flannely, L.T., Flannelly, K.J., \& Jankowski, K.R. (2014). Independent, dependent and other variables in Health care and Chaplaincy research. Journal of Health Care Chaplaincy, 20(2), 61-70.

Fombrun, C., \& Van Riel, C.B.M. (1997). The Reputational Landscape. Corporate Reputation review, 1(1) \& (2), 5-13.

Fombrun, C.J. (1996). Reputation: Realizing Value from Corporate image. Boston, MA.: Havard Business School Press.

Gaultier-Gaillard, S., Louisot, J., \& Rayner, J. (2009). Managing Risks to reputation-from theory to practice. BerlinHeidelberg. Springer.

George, O.J., Owoyemi, O., \& Onakala, U. (2012). Theorizing the Concept of Organizational Artefacts: How it enhances the development of corporate organizational identity. International Journal of Business Administration, 3(4), 37-43.

Ghobadian, A., \& O’Regan, N. (2002). Effective Strategic Planning in Small and Medium sized firms. Management Decision, 40(17), 663-671.

Ghobadian, A., O'Regan, N., \& Sims, M. (2006). Fast Tracking innovation in manufacturing SMEs. Technovation, 26(2), 251-261.

Grant, R.M. (1991). The resource-based theory for competitive advantage. Implications for strategy formulation. CalifoniaManagement, 33(3), 114-135

Günther, L., \& Menzel, D. (2012). Strategizing in SMEs: Between autocratic instructions and autonomous behavior. In 
R. Lang \& E. Müller (Eds.), Proceedings of the International Symposium on Innovation Methods and Innovation Management (pp. 56-69). Chemnitz.

Gupta, A. (2013). Environmental and PEST analysis: An approach to external business environment. Merit Research Journal of Art, Social Science and Humanities, 1(2), 13-17.

Habbershon, T.G., \& Williams, M. L. (1999). A Resource-Based framework for assessing the strategic advantages of family firms. Family Business Review, 12(1), 1-26.

Hart., S., \& Banburry, C. (1994). How strategy-making processes can make a difference. Strategic Management Journal, 15(4), 251-269.

Herath, H.M.A., \&Mahmood, R. (2013). Strategic Based research model of SME Performance for Developing countries. Review of Integrative Business and Business Economics Research, 2(1), 430-440.

Hough, J., Gamble, J.E., Strickland, III A.J., \& Thompson, A.A. (2008). Crafting and Executing Strategy. London: McGrawhill

Hsieh, H., \&Shannon, S.E. (2005). Three Approaches to Qualitative Content Analysis. Qualitative Health Research, 15(9), 1277-1288.

Hughes C. (n.d). Introduction to research methodologies. University of Warwick

Imenda, S. (2014). Is there a conceptual difference between theoretical and conceptual frameworks? Journal of Social Science, 38(2), 185-195.

Jocumsen. (2004). How do small business managers make marketing decisions? A model of process. European Journal of marketing, 38(5), 659:674.

Joppe, M. (2000). The Research Process. Retrieved February 25, 2015, from http://www.ryerson.ca/ mjoppe/rp.html/

Kald, M., \& Nilsson, F. (2000).Performance Management at Nordic companies. European Management Journal, 18(1), 113-127.

Karabulut, T., \& Efendioglu, A.M. (2010). Impact of Strategic Planning on financial companies in Turkey. International Journal of Business Management, 5(4), 201-207.

Kazerooni, E.A. (2001). Population and Sample. Fundamentals of Clinical Research for Radiologists. American Journal of Roentgenology, 177(5), 993-999.

Kee-Luen, W., Thiam-Yong, K., \& Seng-Fook, O. (2013). Strategic Planning and business performance: A study of SMEs in Malaysia. In Proceedings of 3rd Asia-Pacific Business Research Conference 25 - 26 February 2013, Kuala Lumpur, Malaysia, ISBN: 978-1-922069-19-1.

Kitchen, T., \& Ball, A.L. (2014). Quantitative theoretical and conceptual framework use in Agricultural Education research. Journal of Agricultural Education, 55(1), 186-199.

Kraus, S., Reische, S.B., \& Reschke, C. H. (2007). Implications of strategic planning in SMEs for International Entrepreneurship research and practice. European Research and Practice, 32(6), 1-30.

Krippendorff, K. (2004). Content Analysis: An Introduction to Its Methodology (2nd ed.). California: Sage Publications.

Langfield-Smith, K. (1997). Management control systems and strategy: A critical review. Accounting, Organizations and Society, 22(2), 207-232.

Leary, M.R. (1995). Introduction to Behavioural research methods ( ${ }^{\text {nd }}$ ed.). Belmont, CA: Brooks/Cole.

Levy, M., Loebbecke, C., \& Powell, C. (2003). SMEs, co-operation and knowledge sharing: the role of information systems. European Journal of Information Systems, 12(1), 3-17.

Lowell, L. (2012). Impact is strategic management applications: The way forward for small and medium scale enterprise in Africa. International Journal of Science and Research, 3(12), 2172-2173.

Lubatkin, M.H., Ling, Y., \& Simsek, Z. (2006). Ambidexterity and Performance in Small to Medium sized firms: The Pivotal role of Top Management Team Behavioural Integration. Journal of Management, 32(5), 646-672.

Marying, P. (2000). Qualitative content analysis. Qualitative Research Journal, 1(2), 1-10.

Mazzarol, T. (2003). The strategic management of small firms: Does the theory fit the practice? University of Western Australia Discussion Paper, No. 0301. 
Mazzarol, T. (2004). The strategic management of small firms: A proposed framework for Entrepreneurial ventures. Proceedings for the 17th Annual SEAANZ Conference 2004, 26-29 September Entrepreneurship as the way of the Future Brisbane Queensland.

Mbonyane, B., \& Ladzani, W. (2011). Factors that hinder the growth of small businesses in South African townships. European Business Review, 23(6), 550-560.

Miller, D., \& Shamsie, J. (2001). Learning across the life cycle: Experimentation and performance among the Hollywood studio heads. Strategic Management Journal, 22(8), 725-745.

Miller, S., Hickson, D., \&Wilson, D. (2004). Beyond Planning: Strategies for Successfully Implementing Strategic Decisions. Long Range Planning, 37, 201-218.

Mlanya, L.M. (2015). Stakeholder involvement in Strategic management and performance of British-American Investments Company limited (BAICL), (Doctoral Dissertation, University of Nairobi).

Mosoti, Z.M., \& Kamau, M.E. (2014). Assessing the implication of strategic planning on performace of small sized organisations: A case study of small enterprises in Thika town. Journal of Research in Business and Management, 2(3), 01-13.

Mouton, J. (1996). Understanding social research. Van Schaik Publishers.

Neneh, N.B., \&Vanzyl, J. (2012). Achieving business performance through business practices: evidence from SMEs in selected areas in South Africa. South African Business Review, 16(3), 118-144.

Newell, S.J., \& Goldsmith, R.E. (2001). The development of a scale to measure corporate credibility. Journal of Business Research, 52(3), 235-247.

Newton, N. (2010). The use of semi-structured interviews in qualitative research: strengths and weaknesses. Exploring Qualitative Methods. Retrieved December 10, 2015, from www.cademia.edu

Nkwe, N. (2012). Role of SMEs in Botswana. American International Journal of Contemporary Research, 2(8), 39-37.

Nyakiri, R.N. (2013). Strategic management practices as a competitive tool in enhancing performance of small and medium enterprises in Kenya. Unpublished Thesis, University of Nairobi.

Nyamwanza, T., \& Mavhiki, S. (2014). Strategy implementation framework used by SMEs in Zimbabwe. Journal of Business and Management, 3(2), 1-16.

O' Regan, N., \& Ghobadian, A. (2002). Formal strategic planning. Business Process Management Journal, 8(5), 416-429.

OECD. (2013). Financing SMEs and Entrepreneurs 2013: An OECD Scoreboard. OECD Publishing. Retrieved September 18, 2014, from http://dx.doi.org/10.1787/fin_sme_ent-2013-en

Okpara, J.O. (2011). Factors constraining the growth and survival of SMEs in Nigeria: Implications for poverty alleviation. Management Research Review, 34(2), 156-171.

Okpara, J.O., \& Wynn, P. (2007). Determinants of small business growth constraints in a Sub-Saharan African economy. SAM Advanced Management journal, 72(2), 24-35.

Okurut, F.N., Olalekan, Y., \& Mangadi, K. (2011). Credit Rationing and SME development in Botswana: Implications for Economic diversification. Botswana Journal of Economics, 8(12), 62-85.

Olatokun, W., \& Kebonye, M. (2010). E-commerce technology adoption by SMEs in Botswana. International journal of emerging technologies and society, 8(1), 42.

Olawale, F., \& Garwe, D. (2010). Obstacles to the growth of new SMEs in South Africa: A principal component analysis approach. African journal of Business Management, 4(5), 729-738.

Onwuegbuzie, J.A., \& Collinsa, M.T.K. (2007). A typology of mixed methods sampling designs in social science research. The Qualitative Report, 12(2), 281-316.

Pandya, V.M. (2012). Comparative analysis of development of SMEs in developed and developing countries. In Proceedings of the 2012 International Conference on Business and Management, pp. 426-433.

Pansiri, J., \& Temtime, Z.T. (2008). Assessing Managerial skills in SMEs for capacity building. Journal of Management Development, 27(2), 251-260. 
Pemberton, J., \& Stonehouse, G. (2002). Strategic Planning in SMEs- Some empirical findings. Management Decisions, 40(9), 853-861

Piest, B. (1994). Planning Comprehensiveness and Strategy in SMEs. Small Business Economics, 6, 387-395.

Polatoglu, V.N. (2007). Strategies that work- The case of an e-retailer in an emerging market. International Journal of emerging markets, 2(4), 395- 405.

Pole, K. (2007). Mixed method designs. A Review of Strategies for Blending Quantitative and Qualitative Methodologies. Mid-Western Educational Researcher, 20(4), 35-38.

Robson, P.J., \& Obeng, B.A. (2008). The barriers to growth in Ghana. Small Business Economics, 30(4), 385-403.

Salavou, H., Baltas, G., \& Lioukas, S. (2004). Organisational innovation in SMEs: The importance of strategic orientation and competitive structure. European Journal of Marketing, 38(9), 1091-1112.

Sandada, M. (2015). Strategic Planning Dimensions in Small and Medium Enterprises (SMEs) in South Africa: Their relative importance and variations in selected demographic variables. Ecoforum Journal, 4(1), 59-68.

Sandada, M., Pooe, D., \& Dhurup, M. (2014). Strategic Planning and Its Relationship with Business Performance among Small and Medium Enterprises in South Africa. International Business \& Economics Research Journal, 13(3), 659-670.

Sandberg, W.R., Robinson, R.B., \& Pearce, J.A. (2001). Why Small Businesses need a Strategic plan. Business EconomicReview, 48(1), 12-15.

Saunders, M.N.K., Lewis, P., \& Thornhill, A. (2009). Research Methods for Business students (5 ${ }^{\text {th }}$ ed.). Harlow. United Kingdom. Prentice Hall.

Sharma, G. (2011). Do SMEs need to strategize? Business strategy series, 12(4), 186-196.

Sharma, P. (2010). Strategic entrepreneurial behaviours in family businesses. International Journal of Entrepreneurship and Innovation Management, 13(1), 4-11.

Singh, R.K., Garg, S.K., \& Deshmukh, S.G. (2008). Strategy development by SMEs for competitiveness: a review. Benchmarking: An International Journal, 20(1), 97-131.

Stemler, S. (2001). An overview of content analysis. Practical Assessment, Research \& Evaluation, 7(17). Retrieved January 13, 2016, from http://www.PAREonline.net/getvn.asp? $\mathrm{v}=7 \& \mathrm{n}=17$

Stewart, S. (2002). Formal business planning and small business success: A survey of small businesses with an international focus. Journal of American Academy of Business Cambridge, 2(1), 42-46.

Storey, D.J. (1994). Understanding the Small Business Sector. Retrieved July16, 2014, from http://ssrn.com/abstract $=1496214$

Suskie, L.A. (1996). Questionnaire Survey Research: What works. Florida State University: Association for Institutional Research Resources for Institutional Research.\# 6.

Teece, D.J., Pisano, G., \& Shuen, A. (1997). Dynamic capabilities of Strategic Management. Strategic Management Journal, 18(7), 509-533.

Temtime, Z.T. (2001). The Role of Microcomputers in Small and Medium Enterprises: Are They Used in Strategic Decisions and Planning?. Pakisan Journal of Applied Science, 1(2), 87-92.

Temtime, Z.T. (2008). From operating efficiency to competitive edge: lessons from small firms in Botswana. Strategic Change, 17(7-8), 295-306.

Temtime, Z.T., \& Pansiri, J. (2005). Managerial competency and organisational flexibility in small and medium enterprises in Botswana. Problems and Perspectives in Management, 1, 25-36.

Temtime, Z.T., \& Pansiri, J. (2006). Perceived managerial problems in SMEs: evidence from Botswana. Development and Learning in Organisations: An International Journal, 20(5), 15-17.

Temtime, Z.T., \&Pansiri, J. (2004). Small business critical success/failure factors in developing countries: some evidence from Botswana. American Journal of applied Science, 1(1), 18-24.

Theories, concepts and rationale for strategic planning.(n.d.). Retrieved June 20, 2014, from http://www.openuni-clsu.edu.ph/openfiles/modules/ed870/strategic_planning.doc

Torres, O. (2004). The SME concept of Pierre-Andre Julien: An analysis in terms of proximity. Piccola impresa, 
Small Business, 17(2), 51-62.

Udo-Akang, D. (2012). Theoretical Constructs, Concepts, and Applications. American International Journal of Contemporary Research, 2(9), 89-97.

Valentin, E.K. (2001). SWOT analysis from a resource-based view. Journal of marketing theory and practice, 9(2), 54-69.

Veskaisri, K., Chan, P., \& Pollard, D. (2007). Relationship between strategic planning and SMEs success: Empirical evidence from Thailand. Asia and Pacific DSI.

Wacker, J. (1998). A definition of Theory: Research guidelines for different theory- building research methods in operation management. Journal of operations management, 16(4), 361-385.

Wang, C., Walker, E.A., \& Redmond, J. (2007). Explaining the lack of Strategic Planning in SMEs: The importance of owner motivation. International Journal of Organizational Behaviour, 12(1), 1-16.

Weiglet, K., \& Camerer, C. (1988). Reputation and Corporate Strategy: A review of recent theory and application. Strategic Management Journal, 9(5), 443-454.

Yang, K., \& Miller, G.J. (2008). Handbook of research methods in public administration (2nd ed.). New York: M. Dekker.

Yang, W.L., \& Li, J.X. (2007). Study on reputation strategy of corporation. Research of Organisational Innovation-2007. Proceeding of International conference on Enterprise Engeneering and Management Innovation, pp. 198-204.

Yu, F., \& Teddie, C. (2007). Mixed method sampling: A Topology with examples. Journal of Mixed Methods Research, 1(1), 77-100.

Zack, M.H.(Ed.). (2009). Knowledge and Strategy. Business and Economics. Routledge.

\section{APPENDIX 1}

\section{Interview Questionnaire}

I am Nomsa Majama, a master's research student in the department of management at the University of Botswana. This research project is conducted as part of the MBA Programme that I have enrolled for. The purpose of this study is to evaluate the extent of strategic planning by Small and Medium Enterprises (SMEs) in Botswana. The study is beneficial to both the researcher and participant as it highlights the elements of the planning process and the importance of strategic planning which may be incorporated to improve on the strategic planning activity, this will be of value to SMEs.

The research intends to cause no harm or offense and to abide by all commonly acknowledged ethical codes. You have the right to ask the researcher any questions regarding this research. You also have the right to reject participation or withdraw from this research any time you wish. The questionnaire is voluntary and the data collected is strictly confidential, only the researcher will have access to view the data collected during this research. You agree to participate in this research project by responding to the questions.

This may take 25 minutes of your time. Please answer the questions to the best of your ability. Your participation is greatly appreciated.

Thank you for your participation

Nomsa Majama

72908665/71642561 


\section{SECTION A- DEMOGRAPHICS}

1. Respondent's Demographics

1a. Gender:

Male

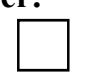

Female $\square$

1b. Age of Respondent:

Below 21

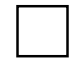

49-62 years

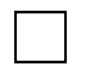

21-34 years

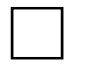

35-48 years

62 and above

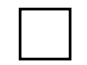

\section{1c. Level of Education}

PSLE

JC

$\square \quad$ BGCSE

Degree $\square$ Other (Specify)

\section{Firm Demographics}

2a. Number of employees:

Less than 6

6-15

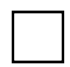

$16-24$

$25-49$

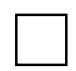

50-99

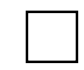

more than 99

2b. Annual turnover:

Less than 60000

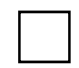

$60000-499000$

$500000-1.5 \mathrm{~m}$

$1.6 \mathrm{~m}-2.5 \mathrm{~m}$

$2.6 m-5 m$

Over $5 \mathrm{~m}$

2c. Age of the firm:

Less than 1 year

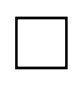

1-3 years

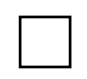

4-6 years

7-9 years

4More than 10

\section{2d. Type of industry:}

Services

Agri- business

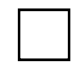

Construction

Manufacturing

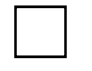

Retail

Other(specify) 


\section{SECTION B- STRATEGY FORMULATION}

1. Does your organization have a vision, mission and long-term objectives?

\begin{tabular}{|l|l|l|}
\hline & Yes & No \\
\hline Vision & & \\
\hline Mission & & \\
\hline Long term objectives? & & \\
\hline
\end{tabular}

Please state your Mission and/or Vision if your answer above is YES.

Mission

Vision

2. Does you organization have a formulated and documented game plan on how to achieve the above?

1) Very precisely

2) Approximately

3) No

3. Does your organization incorporate this paln in your daily activities?

1) Very precisely

2) Approximately

3) No

4. Business planning in your organization is for a period of how long?

Less than 1 year

1-2 years

3-4 years

5-6 years

More than 5 years

\section{Who is involved in business planning?}

Business Owners only

Senior management

Other (Specify)
Business Owners and Chief Executives

Managers from all levels

6. What forms the basis for the decision on the plan that your firm follows?

1) Analysis of the market and competition

2) Analysis of internal capabilities of the firm

3) Analysis of internal and external performance of the firm

4) Feeling based(intuition of entrepreneurs/manager)

5) Other 


\section{SECTION C- BARIERS TO STRATEGIC PLANNING}

1. What are the factors that hinder your firm from engaging in business planning activities

\begin{tabular}{|ll|l|}
\hline 1) & Insufficient knowledge of the planning process & \\
\hline 2) & Rejection of external assistance & \\
\hline 3) & Tradition-based thinking & \\
\hline 4) & Fear of radical change & \\
\hline 5) & Lack of time & \\
\hline 6) & Size of business & \\
\hline 7) & Others & \\
\hline
\end{tabular}

2. To what extent do the factors stated above affect planning? 5-To a large extent and 0-Not at all

\begin{tabular}{|l|l|l|l|l|l|l|}
\hline & $\mathbf{0}$ & $\mathbf{1}$ & $\mathbf{2}$ & $\mathbf{3}$ & $\mathbf{4}$ & $\mathbf{5}$ \\
\hline 1) Insufficient knowledge of the planning process & & & & & & \\
\hline 2) Rejection of external assistance & & & & & & \\
\hline 3) Tradition-based thinking & & & & & & \\
\hline 4) Fear of radical change & & & & & & \\
\hline 5) Lack of time & & & & & & \\
\hline 6) Size of business & & & & & & \\
\hline 7) Type of industry & & & & & & \\
\hline 8) Others & & & & & & \\
\hline
\end{tabular}




\section{SECTION D}

1. Do you set long-term business objectives for the SME? Give examples if you do.

2. What are the activities involved in the planning process?

3. Which is the most important in the list above and why?

4. What planning tools do you use?

5. How do you measure performance to track the success of devised plans?

6. What approach does the firm apply to survive competition and why have you decided on this approach?

7. Do you think it is important for your firm to have a business plan and why? 


\section{Appendix II}

Interview Coding Template

Section D

1. Do you set long -term business objectives for the SME? Give Examples

a) Growth/Diversity of Business Operations

b) Learning and expansion of skills

c) Increase revenue

d) No objectives

2. What are the activities involved in planning process

a) Financial Revenue Planning

b) Business Growth/Objectives

c) Product/Services Review

d) Market Analysis

e) Client Relationship Management

f) Combination of two or more

3. What planning tools do you use?

a) SWOT

b) Budgets, Financial forecast

c) Market survey/Analysis

d) Combination of tools

e) No Tools

4. How do you measure performance to track the success of devised plans

a) Financial performance

b) Customer growth

c) Set milestones/Output

d) Staff retention

e) Feedback review

f) Combination

5. What approach does the firm apply to survive competition and why have you decided on this approach?

a) Low prices

b) Intense Marketing

c) Offering quality

d) Differentiation

e) Customer satisfaction

f) Focus on a niche

g) Combination of approaches

6. Do you think it is important for your firm to have a business plan and why?

a) Yes it is important

b) No it is not important 